\title{
Search, Migration, and Urban Land Use: The Case of Transportation Policies*
}

\author{
Yves Zenou ${ }^{\dagger}$ \\ Stockholm University, IFN, and CEPR
}

November 6, 2010

\begin{abstract}
We develop a search-matching model with rural-urban migration and an explicit land market. Wages, job creation, urban housing prices are endogenous and we characterize the steady-state equilibrium. We then consider three different policies: a transportation policy that improves the public transport system in the city, an entry-cost policy that encourages investment in the city and a restricting-migration policy that imposes some costs on migrants. We show that all these policies can increase urban employment but the transportation policy has much more drastic effects. This is because a decrease in commuting costs has both a direct positive effect on land rents, which discourages migrants to move to the city, and a direct negative effect on urban wages, which reduces job creation and thus migration. When these two effects are combined with search frictions, the interactions between the land and the labor markets have amplifying positive effects on urban employment. Thus, improving the transport infrastructure in cities can increase urban employment despite the induced migration from rural areas.
\end{abstract}

JEL Classifications: D83, J61, O18, R14.

Keywords: Rural-urban migration, transportation policies, entry costs, restricting migration.

*I thank the editor, Maitreesh Ghatak, and two anonymous referees for helpful comments.

${ }^{\dagger}$ E-mail: yves.zenou@ne.su.se. This paper was partly written while I was visiting the University of California, Berkeley. Their hospitality is gratefully acknowledged. 


\section{Introduction}

Cities of the developing world are often characterized by their large size, high unemployment, high poverty, a large fraction of rural migrants, and poor transport infrastructure. It is our contention that these different characteristics are strongly linked together and only policies taking into account all these aspects and thus the interaction between different markets can be successful. In particular, we believe that the lack of good transport system in developing cities can have a big influence on labor market outcomes. A good example is India where the overall population growth and increasing urbanization have led to the especially rapid growth of large cities, ${ }^{1}$ so that the poor population must spend up to three or four hours a day for travel (Pucher et al., 2005). ${ }^{2}$ Improving the transport system in such a country can have important effects on workers' labor market outcomes.

We thus need to develop a model where all these features are present. The Harris-Todaro framework (Todaro, 1969; Harris and Todaro, 1970) has become a cornerstone of models of rural-urban migration. The aim of the Harris-Todaro framework is to explain the persistent rural-urban migration in developing countries despite the high unemployment rates in cities. The original model has been extended in different directions (see the literature surveys by Basu, 1997, Part III; Ray, 1998, Chap. 10) to explain this puzzle. We believe that two aspects are particularly important in order to tackle the issues mentioned above and should be introduced if one wants to understand the policy implications of such a model. First, one should consider a search-matching labor market in the city in order to endogeneize wages and unemployment. Indeed, there are large evidence showing that cities in developing countries are characterized by important search frictions due to coordination failures, mismatch costs and lack of information about jobs (see, e.g., Rama, 1998; Bosch et al., 2007; Bosch and Maloney, 2008). Second, an explicit land/housing market should be incorporated in the city to study the relationship between rural-urban migration and the land market. Indeed, a city differs from a rural area not only because of the specificity of its labor market (as in the standard Harris-Todaro model) but also because of its land/housing market.

\footnotetext{
${ }^{1}$ By 2001, India had three megacities: Mumbai (Bombay) with 16.4 million inhabitants, Kolkata (Calcutta) with 13.2 million inhabitants, and Delhi with 12.8 million inhabitants. And 35 metropolitan areas had populations exceeding one million, almost twice as many as in 1991 (Office of the Registrar General of India, 2001).

${ }^{2}$ See also Carruthers et al. (2005) who show that workers in developing countries spend a significant amount of their income on transportation.
} 
There is a tradition of search models in the migration literature that only model one side of the market (the workers) so that firms' behavior and thus job creation are not considered (see e.g. Fields, 1975, 1989, Banerjee, 1984, Mohtadi, 1989). There is a more recent literature, which incorporates a search-matching labor market a la Pissarides-Mortensen (Mortensen and Pissarides, 1999; Pissarides, 2000) in a Harris-Todaro model (see Coulson et al., 2001; Ortega, 2000; Sato, 2004; Laing et al., 2005; Zenou, 2008; Albrecht et al., 2009; Satchi and Temple, 2009). ${ }^{3}$ None of these models, however, have an explicit land market where workers choose their residential location in the city.

In this paper, we propose a rural-urban migration model where the city is characterized by both a search-matching labor market and an explicit land/housing market. To the best of our knowledge, this is the first paper that performs such an analysis. This allows us not only to characterize and to study the properties of the steady-state equilibrium but also to analyze the impact of three policies on labor-market outcomes. ${ }^{4}$

To be more precise, we develop a model where there are search frictions in the city so that unemployment prevails there ${ }^{5}$ whereas the rural area is competitive. In the city, the wage is determined by a bargaining between workers and firms and because of search frictions, unemployment emerges in equilibrium. In the rural area, workers are paid at their marginal productivity, so that there is full employment. Depending on their employment status, workers optimally decide whether to live in the city or in the rural area. We characterize the steady-state equilibrium of the economy with rural-urban migration and show that the equilibrium exists and is unique but not efficient because of search externalities. We then consider three different policies: a transportation policy that improves the public transport system in the city, an entry-cost policy that encourages investment in the city and

\footnotetext{
${ }^{3}$ For an overview, see Zenou (2009).

${ }^{4}$ There are few theoretical papers analyzing transport policies in an explicit urban framework (exceptions include Zenou, 2000; Borck and Wrede, 2005; 2009; Brueckner, 2006; Brueckner and Selod, 2006; Wrede 2001) and even less papers studying the impact of such policies on labor-market outcomes of workers (exception includes Zenou, 2000, who looks at an efficiency wage model with no rural-urban migration). Van Ommeren et al. (1999), Van Ommeren and Rietveld (2005), and De Borger (2009) study commuting issues in a search model but there is no land market.

${ }^{5}$ Cities in less developed countries are often characterized by an informal sector. In our analysis, the unemployed workers are basically the infomal workers. In this perspective, the informal sector would be a disadvantaged sector in a segmented labor market where informal workers would try to obtain a formal job. This is certainly true in African countries but less true in Latin American ones (Maloney, 2004).
} 
a restricting-migration policy that imposes some costs on migrants. We show that all policies can increase urban employment but the transportation policy has much more drastic effects. This is because a decrease in commuting costs has both a direct negative effect on land rents, which encourages migrants to move to the city, and a direct negative effect on urban wages, which reduces job creation and thus migration. When these two effects are combined with search frictions, the interactions between the land and the labor markets have amplifying positive effects on urban employment. Thus, improving the transport infrastructure in cities can have important positive effects on urban employment despite the induced migration from rural areas.

\section{Model and notations}

There are two areas: an urban area (the city, denoted by the superscript $C$ ) and a rural area (denoted by the superscript $R$ ). As in the standard Harris-Todaro model, in rural areas, it is assumed that workers are paid at their marginal productivity so that there is no unemployment. Therefore, if $N$ denotes the total population in the economy, the total population in rural areas is $L^{R}=N^{R}$, where $L^{R}$ is the employment level. As a result, the total population in cities is equal to: $N^{C}=L^{C}+U^{C}$ (where $L^{C}$ and $U^{C}$ are respectively the employment and unemployment levels in cities), with $N=N^{C}+N^{R}$. In this context, the unemployment level in cities is given by:

$$
U^{C}=N-L^{C}-L^{R}
$$

\section{$2.1 \quad$ The city}

It is assumed that there are search frictions ${ }^{6}$ in the city and we use the standard search matching framework (Mortensen and Pissarides, 1999; Pissarides, 2000) to model these frictions. There is a continuum of firms. A firm is a unit of production that can either be filled by a worker whose production is $y$ units of output or be unfilled and thus unproductive. In order to find a worker, a firm posts a vacancy. A vacancy can be filled according to a random Poisson process. Similarly, workers searching for a job will find one according to

\footnotetext{
${ }^{6}$ As defined by Mortensen and Pissarides (1999), "market friction is the costly delay in the process of finding trading partners and determining the terms of trade." In other words, search frictions imply that it takes time and other resources for a worker to obtain a job and for a firm to fill a vacancy.
} 
a random Poisson process. In aggregate, these processes imply that there is a number of contacts per unit of time between the two sides of the market that are determined by the following matching function: ${ }^{7}$

$$
\Omega\left(\bar{s} U^{C}, V^{C}\right)
$$

where $\bar{s}$ is the average search efficiency of the unemployed workers and $V^{C}$ denotes the total number of vacancies in the city. It is assumed that $s=\bar{s}$, so each worker provides the same search effort $s$, which is exogenous. As in the standard search-matching model (see e.g. Mortensen and Pissarides, 1999, and Pissarides, 2000), we assume that $\Omega($.$) is increasing$ both in its arguments, concave and homogeneous of degree 1 (or equivalently has constant return to scale). Thus, the rate at which vacancies are filled is $\Omega\left(\bar{s} U^{C}, V^{C}\right) / V^{C}$. By constant returns to scale, it can be rewritten as

$$
\Omega\left(1 / \theta^{C}, 1\right) \equiv q\left(\theta^{C}\right)
$$

where

$$
\theta^{C}=\frac{V^{C}}{s U^{C}}
$$

is a measure of labor market tightness in efficiency units and $q\left(\theta^{C}\right)$ is a Poisson intensity. By using the properties of $\Omega($.$) , it is easily verified that q^{\prime}\left(\theta^{C}\right) \leq 0$ : the higher the labor market tightness, the lower the rate at which firm fill their vacancy. Similarly, the rate at which an unemployed worker with search intensity $s$ leaves unemployment is

$$
\frac{s}{\bar{s}} \Omega\left(\bar{s} U^{C}, V^{C}\right) \equiv a\left(\theta^{C}\right)
$$

where $a\left(\theta^{C}\right) \equiv s \theta^{C} q\left(\theta^{C}\right)$ is the job-acquisition rate. Again, by using the properties of $\Omega($.$) , it$ is easily verified that $a^{\prime}\left(\theta^{C}\right) \geq 0$ : the higher the labor market tightness, the higher the rate at which workers leave unemployment since there are relatively more jobs than unemployed workers. Also, the higher the search intensity $s$ (unemployed search more actively for jobs), the higher is this rate $a\left(\theta^{C}\right)$. Finally, the rate at which jobs are destroyed is exogenous and denoted by $\delta$.

If there are no frictions in this model, then unemployment and vacancies disappear, and jobs are found and filled instantaneously. Indeed,

$$
\lim _{\theta^{C} \rightarrow 0} a\left(\theta^{C}\right)=\lim _{\theta^{C} \rightarrow+\infty} q\left(\theta^{C}\right)=0
$$

\footnotetext{
${ }^{7}$ This matching function is written under the assumption that the city is monocentric, i.e. all firms are located in one fixed location.
} 
and

$$
\lim _{\theta^{C} \rightarrow+\infty} a\left(\theta^{C}\right)=\lim _{\theta^{C} \rightarrow 0} q\left(\theta^{C}\right)=+\infty
$$

That is, if $\theta^{C} \rightarrow 0$, then the number of unemployed is infinite and thus firms filled their job instantaneously (no frictions on the firm's side), whereas if $\theta^{C} \rightarrow+\infty$, then the number of vacancies is infinite and thus workers find a job instantaneously (no frictions on the worker's side).

\subsection{The rural area}

There is no unemployment in rural areas. ${ }^{8}$ Everybody can thus obtain a job in the rural area and it is assumed that the rural wage is flexible enough to guarantee that there is full-employment; this wage is denoted by $w_{L}^{R}$. We have the following production function:

$$
F\left(L^{R}\right) \quad \text { with } F^{\prime}\left(L^{R}\right)>0 \text { and } F^{\prime \prime}\left(L^{R}\right) \leq 0
$$

which means that the rural productivity per worker is $y^{R}=F\left(L^{R}\right) / L^{R}$. The price of the good is taken as a numeraire and, without loss of generality, normalized to 1 . As stated above, in the rural area, wages are flexible and equal to workers' marginal product. We thus have:

$$
w_{L}^{R}=F^{\prime}\left(L^{R}\right)
$$

A steady-state equilibrium in the city requires solving simultaneously an urban land-use equilibrium and a labor-market equilibrium. For presentation convenience, we first present the former and then the latter.

\subsection{Urban-land use equilibrium}

There is a continuum of equally productive workers whose mass is $N^{C}$ and who are uniformly distributed along a linear and monocentric city. All land is owned by absentee landlords and all firms are exogenously located in the Central Business District (CBD hereafter). There is no vacant land. The CBD is a unique employment center located at one end of the linear

\footnotetext{
${ }^{8}$ In rural areas, most workers are employed within the broader context of the family, so search frictions are liable to be small. As a result, we only assume search frictions in the city.
} 
city. Without loss of generality, the density of residential land parcels is taken to be unity, so that there are exactly $x$ units of housing within a distance $x$ from the CBD. Workers decide their optimal place of residence between the CBD and the city fringe.

Each individual is identified with one unit of labor. Each employed worker goes to the CBD to work and incurs a fixed monetary commuting cost $\tau$ per unit of distance. When living at a distance $x$ from the CBD, he/she also pays a land rent $R(x)$, consumes 1 unity of land and earns a wage $w_{L}^{C}$ (that will be determined at the labor market equilibrium). ${ }^{9}$ The instantaneous (indirect) utility of an employed worker located at a distance $x$ from the CBD is thus equal to:

$$
W_{L}^{C}(x)=w_{L}^{C}-\tau x-R^{C}(x)
$$

Concerning the unemployed workers, we assume that they do not receive any unemployment benefit, as it is the case in most developing countries. ${ }^{10}$ Moreover, they commute less often to the CBD than the employed workers since they mainly go there to search for jobs. So, we assume that they incur a commuting cost $s \tau$ per unit of distance, where $0<s \leq 1$ is a measure of search intensity. For example $s=1$ would mean that the unemployed workers go everyday to the CBD (as often as the employed workers) to search for jobs. Observe that here we assume that the unemployed workers need to go to the CBD to obtain information about jobs and this is why they need to commute there. If, for example, $s=0$, which we exclude here, then they would never find a job. The instantaneous (indirect) utility of an unemployed worker residing at a distance $x$ from the CBD is equal to:

$$
W_{U}^{C}(x)=-s \tau x-R^{C}(x)
$$

An urban equilibrium is such that all the employed workers enjoy the same level of utility $W_{L}^{C}$ while all the unemployed workers obtain $W_{U}^{C}$. Bid rents ${ }^{11}$ are respectively given by:

$$
\begin{gathered}
\Psi_{L}\left(x, W_{L}^{C}\right)=w_{L}^{C}-\tau x-W_{L}^{C} \\
\Psi_{U}\left(x, W_{U}^{C}\right)=-s \tau x-W_{U}^{C}
\end{gathered}
$$

\footnotetext{
${ }^{9}$ The subscript $L$ refers to the employed workers whereas the subscript $U$ refers to the unemployed workers.

${ }^{10}$ None of our results will be affected with positive unemployment benefits.

${ }^{11}$ The bid rent indicates the maximum land rent that a worker located at a distance $x$ from the CBD is ready to pay in order to achieve an equilibrium utility.
} 
They are both linear and decreasing in $x$. Because employed workers experience higher commuting costs, they have steeper bid rents and thus reside closer to the CBD.

Definition 1 An urban-land use equilibrium is a 3-tuple $\left(W_{L}^{C *}, W_{U}^{C *}, R^{C *}(x)\right)$ such that:

$$
\begin{gathered}
\Psi_{L}\left(L^{C}, W_{L}^{C *}\right)=\Psi_{U}\left(L^{C}, W_{U}^{C *}\right) \\
\Psi_{U}\left(N^{C}, W_{U}^{C *}\right)=R_{A}=0 \\
R^{*}(x)=\max \left\{\Psi_{L}\left(x, W_{L}^{C *}\right), \Psi_{U}\left(x, W_{U}^{C *}\right), 0\right\} \quad \text { at each } x \in\left(0, N^{C *}\right]
\end{gathered}
$$

Equations (11) and (12) reflect the equilibrium conditions in the land market. Equation (11) says that, in the land market, at the frontier $L^{C}$ between the employed and unemployed workers, the bid rent offered by the employed is equal to the bid rent offered by the unemployed workers. Equation (12), in turn, says that the bid rent of the unemployed workers must be equal to the agricultural land $R_{A}$ (which is normalized to zero) at the city fringe. Finally, equation (13) defines the equilibrium land rent as the upper envelope of the equilibrium bid rent curves of all workers and the agricultural rent line. Figure 1 illustrates this equilibrium.

\section{[Insert Figure 1 here]}

By solving (11) and (12), we easily obtain the equilibrium values of the instantaneous utilities of the employed and the unemployed workers in the city. They are given by:

$$
\begin{gathered}
W_{L}^{C *}=w_{L}^{C}-\tau L^{C}-s \tau\left(N^{C}-L^{C}\right) \\
=w_{L}^{C}-\tau L^{C}-s \tau\left(N-L^{R}-L^{C}\right) \\
W_{U}^{C *}=-s \tau N^{C}=-s \tau\left(N-L^{R}\right)
\end{gathered}
$$

The employment zone (i.e. the residential zone for employed workers) is: $\left[0, L^{C}\right]$ while the unemployment zone (i.e. the residential zone for unemployed workers) is: $\left[L^{C}, N^{C}\right]$. By plugging (14) and (15) into (9) and (10), we easily obtain the land rent equilibrium $R^{C *}(x)$. It is given by:

$$
R^{C *}(x)= \begin{cases}\tau\left(L^{C}-x\right)+s \tau\left(N-L^{R}-L^{C}\right) & \text { for } 0 \leq x \leq L^{C} \\ s \tau\left(N-L^{R}-x\right) & \text { for } L^{C}<x \leq N^{C} \\ 0 & \text { for } x>N^{C}\end{cases}
$$


The main difference with the spatial model without migration (Wasmer and Zenou, 2002; 2006) is that the utility of urban workers as well as the equilibrium land rent now depend on $L^{R}$, the employment level of rural workers. This is because rural-urban migration affects urban land prices. In particular, one can see that, everywhere in the city, i.e. $\forall x \in\left[0, N^{C}\right]$,

$$
\frac{\partial R^{*}(x)}{\partial L^{R}}<0
$$

Indeed, since $L^{R}$ will be determined by an equilibrium migration condition (see below), then when more workers are employed in the rural area, there is less migration to the city and thus less competition in the urban land market so that housing prices decrease.

\subsection{Labor equilibrium in cities}

We are now able to solve the labor market equilibrium and thus the steady-state equilibrium. We have:

Definition $2 A$ (steady-state) labor market equilibrium $\left(w_{L}^{*}, \theta^{C *}, L^{C *}\right)$ is such that, given the matching technology $M(\cdot)$, all agents (workers and firms) maximize their respective objective function, i.e. this triple is determined by a steady-state condition, a free-entry condition for firms and a wage-setting mechanism.

In steady-state, the Bellman equations for the employed and unemployed workers are given by:

$$
\begin{gathered}
r I_{L}^{C}=w_{L}^{C}-\tau L^{C}-s \tau\left(N-L^{R}-L^{C}\right)-\delta\left(I_{L}^{C}-I_{U}^{C}\right) \\
r I_{U}^{C}=-s \tau\left(N-L^{R}\right)+a\left(\theta^{C}\right)\left(I_{L}^{C}-I_{U}^{C}\right)
\end{gathered}
$$

where $r$ is the exogenous discount rate, and $I_{L}^{C}$ and $I_{U}^{C}$ denote the expected lifetime utility of an employed worker and a job seeker, respectively. The first equation that determines $I_{L}^{C}$ states that an employed worker obtains today $W_{L}^{C *}=w_{L}^{C}-\tau L^{C}-s \tau\left(N-L^{R}-L^{C}\right)$ but can loose his/her job at rate $\delta$ and then obtains a negative surplus of $I_{U}^{C}-I_{L}^{C}$. For the job seeker, $I_{U}$ states that he/she obtains $W_{U}^{C *}=-s \tau\left(N-L^{R}\right)$ today but may find a job at rate $a\left(\theta^{C}\right)$, and then obtains a surplus equals to $I_{L}^{C}-I_{U}^{C}$. Because there are no relocation 
costs, in equilibrium all workers must reach the same utility level independently of their location in the city, i.e. $I_{L}^{C}=\bar{I}_{L}^{C}$ and $I_{U}^{C}=\bar{I}_{U}^{C}$. Combining (17) and (18), we obtain:

$$
\bar{I}_{L}^{C}-\bar{I}_{U}^{C}=\frac{w_{L}^{C}-(1-s) \tau L^{C}}{r+\delta+a\left(\theta^{C}\right)}
$$

We denote respectively by $I_{F}^{C}$ and $I_{V}^{C}$ the intertemporal profit of a job and of a vacancy in the city. If $\gamma$ is the search cost for the firm per unit of time and $y^{C}$ is the product of the match, then, in steady-state, $I_{F}^{C}$ and $I_{V}^{C}$ can be written as:

$$
\begin{gathered}
r I_{F}^{C}=y^{C}-w_{L}^{C}-\delta\left(I_{F}^{C}-I_{V}^{C}\right) \\
r I_{V}^{C}=-\gamma+q\left(\theta^{C}\right)\left(I_{F}^{C}-I_{V}^{C}\right)
\end{gathered}
$$

which implies that:

$$
I_{F}^{C}-I_{V}^{C}=\frac{y^{C}-w_{L}^{C}+\gamma}{r+\delta+q\left(\theta^{C}\right)}
$$

We assume that firms post vacancies up to a point where:

$$
I_{V}^{C}=0
$$

This is a free-entry condition. From (22) and using (21), the value of a job is now equal to:

$$
I_{F}^{C}=\frac{\gamma}{q\left(\theta^{C}\right)}
$$

Finally, plugging (23) into (20) and using (22), we obtain the following decreasing relation between labor market tightness and wages in equilibrium:

$$
\frac{\gamma}{q\left(\theta^{C}\right)}=\frac{y^{C}-w_{L}^{C}}{r+\delta}
$$

In words, the value of an urban job is equal to the expected search cost, i.e. the cost per unit of time multiplied by the average duration of search for the firm. So, firms' job creation is endogenous and determined by (24).

Let us now calculate the wage. At each period, the total intertemporal surplus is shared through a generalized Nash-bargaining process between the firm and the worker. The total surplus is the sum of the surplus of the workers, $\bar{I}_{L}^{C}-\bar{I}_{U}^{C}$, and the surplus of the firms $I_{F}^{C}-I_{V}^{C}$. At each period, the wage is determined by:

$$
w_{L}^{C}=\arg \max _{w_{L}^{C}}\left(\bar{I}_{L}^{C}-\bar{I}_{U}^{C}\right)^{\beta}\left(I_{F}^{C}-I_{V}^{C}\right)^{1-\beta}
$$


where $0 \leq \beta \leq 1$ is the bargaining power of workers. By solving this equation, we easily obtain:

$$
w_{L}^{C}=(1-\beta)(1-s) \tau L^{C}+\beta\left(y^{C}+\gamma s \theta^{C}\right)
$$

It is worth noting that space only enters here in the wage equation by adding one new term $(1-\beta)(1-s) \tau L^{C}$ (Wasmer and Zenou, 2002; 2006). This is what firms must pay to induce workers to accept the job offer: firms must exactly compensate the transportation cost difference (between the employed and the unemployed) of the employed worker who is the furthest away from the CBD, i.e. located at $x=L^{C}$. All the other effects are similar to the ones found in the non-spatial model (Pissarides, 2000). By combining (24) and (26), we obtain the equation defining $\theta^{C *}$. It is given by:

$$
y^{C}=\frac{\gamma}{(1-\beta)}\left[\frac{r+\delta+\beta a\left(\theta^{C *}\right)}{q\left(\theta^{C *}\right)}\right]+(1-s) \tau L^{C *}
$$

Compared to the non-spatial model, the main difference is that now $\theta^{C *}$ is a function of $L^{C *}$ through the spatial cost compensation $(1-s) \tau L^{C *}$. Not surprisingly, an increase in $L^{C *}$ decreases urban job creation since it augments $(1-s) \tau L^{C *}$ and thus the wage, which, in turn, deters entry.

Let us now close the model. Each job is destroyed according to a Poisson process with arrival rate $\delta$. Thus, the number of workers who enter unemployment in the city is $\delta L^{C}$ and the number who leave unemployment is $s \theta^{C} q(\theta)^{C}\left(N-L^{C}-L^{R}\right)$ since $U^{C}=N-L^{C}-L^{R}$ (see $(1)$ ). In steady-state, flows in and out unemployment have to be equal and we obtain the following steady-state relationship between urban and rural employments:

$$
L^{C *}=\frac{a\left(\theta^{C *}\right)}{\delta+a\left(\theta^{C *}\right)}\left(N-L^{R *}\right)
$$

Again, compared to the spatial model without migration, in addition to the relationship between $L^{C *}$ and $\theta^{C *}$, there are now two new relationships, one between $L^{C *}$ and $L^{R *}$, and one between $\theta^{C *}$ and $L^{R *}$. For a given $\theta^{C *}$, an increase in $L^{R *}$ reduces $L^{C *}$. Also, for a given $L^{C *}$, the relationship between $\theta^{C *}$ and $L^{R *}$ is positive. Indeed, when more workers are employed in the rural area, urban employment has to decrease for (28) to hold. Similarly, if urban employment is fixed, then job creation has to increase following an increase in rural employment for (28) to hold. 


\subsection{Rural-urban migration}

Concerning rural-urban migration, we assume that a rural worker cannot search from home but must first be unemployed in the city (to gather information about jobs) and then searches for a job. There are plenty of evidence, especially in developing countries, showing that to obtain an urban (formal) job, one needs local contacts and local information about jobs (see e.g. Banerjee, 1984; Wahba and Zenou, 2005). As a result, as described in Figure 1, a rural worker who migrates to the city will first reside in the unemployment area anywhere between $x=L^{C}$ and $x=N^{C}=N-L^{R}$. Thus, the equilibrium migration condition can be written as:

$$
I_{U}^{C}=\int_{0}^{+\infty}\left(w_{L}^{R}-R_{A}\right) e^{-r t}
$$

That is rural workers will migrate to the city up to the point where their expected lifetime utility is equal to the expected utility they will obtain in cities as unemployed workers. Indeed, the left-hand side of this equation, $I_{U}^{C}$, is the intertemporal utility of moving to the city (remember that a migrant must first be unemployed) while, the right-hand side, $\int_{0}^{+\infty}\left(w_{L}^{R}-R_{A}\right) e^{-r t}=\left(w_{L}^{R}-R_{A}\right) / r$, corresponds to the intertemporal utility of staying in rural areas. By using (6), (18), (19), (26), and remembering that $R_{A}=0$, the migration equilibrium condition (29) can be written as:

$$
a\left(\theta^{C *}\right) \beta\left[y^{C}+\gamma s \theta^{C *}-(1-s) \tau L^{C *}\right]=\left[F^{\prime R}\left(L^{R *}\right)+s \tau\left(N-L^{R *}\right)\right]\left[r+\delta+a\left(\theta^{C *}\right)\right]
$$

\section{Steady-state equilibrium}

We have the following definition.

Definition 3 An Harris-Todaro equilibrium with search externalities and a land market is a 6-tuple $\left(\theta^{C *}, L^{C *}, L^{R *}, W_{L}^{C *}, W_{U}^{C *}, R^{C *}(x)\right)$ such that (27), (28), (30), (14), (15) and (16) are satisfied.

In fact, there are three unknowns $\theta^{C *}, L^{C *}$, and $L^{R *}$ and three equations (27), (28), and (30), to be determined (the other equations are independent). By plugging the value of $L^{C *}$ from (28) into (27) and (30), we easily obtain:

$$
y^{C}=\frac{\gamma}{q\left(\theta^{C *}\right)}\left[\frac{r+\delta+\beta a\left(\theta^{C *}\right)}{1-\beta}\right]+(1-s) \tau \frac{a\left(\theta^{C *}\right)}{\delta+a\left(\theta^{C *}\right)}\left(N-L^{R *}\right)
$$




$$
\begin{aligned}
& a\left(\theta^{C *}\right) \beta\left[y^{C}+\gamma s \theta^{C *}-(1-s) \frac{\tau\left(N-L^{R *}\right) a\left(\theta^{C *}\right)}{\delta+a\left(\theta^{C *}\right)}\right] \\
= & {\left[F^{\prime R}\left(L^{R *}\right)+s \tau\left(N-L^{R *}\right)\right]\left[r+\delta+a\left(\theta^{C *}\right)\right] }
\end{aligned}
$$

As a result, we end up with two unknowns $\theta^{C *}$ and $L^{R *}$ and two equations (31) and (32).

Equation (31) is the job-creation condition (or labor demand) that defines a relationship between $\theta^{C *}$ and $L^{R *}$, i.e., $\theta^{C *}=\theta^{C}\left(L^{R *}\right)$. It is really the urban land market that introduces this relationship through the spatial compensation costs $(1-s) \tau L^{C *}$. In a standard nonspatial model (as in Pissarides, 2000), $\tau=0$, and this equation defines a unique $\theta^{C *}$ as a function of parameters only. Equation (32) is the rural-urban migration condition that defines a relationship between $L^{R *}$ and $\theta^{C *}$, i.e., $L^{R *}=L^{R}\left(\theta^{C *}\right)$. Indeed, job creation in cities affects rural-urban migration because better employment prospects in cities trigger more migration.

It is easy to show that there exists a unique steady-equilibrium. This equilibrium is not efficient because of search and migration externalities. So we would like now to consider different policies that aim at reducing urban unemployment and increasing urban employment.

\section{Policies}

\subsection{Transportation policies}

As stated in the Introduction, our aim is to evaluate transportation policies. We look here at a decrease in commuting costs $\tau$ for all workers. This is the case, for example, when the local government invests in transportation infrastructures (for example, building new roads) or in improving the city transportation network (adding new buses or trains). This will, obviously, reduce the costs of commuting of all workers in the city. For example, in India, the public transport system is very bad since most buses and trains in cities are old and poorly designed, inadequately maintained, dangerously overcrowded, undependable, and slow (Acharya, 2000). Subsidizing commuting costs in our model is equivalent to expanding and improving public transport systems. ${ }^{12}$

\footnotetext{
${ }^{12}$ Urban road pavement is also a way of improving transportation in developing countries. See, in particular, Gonzalez-Navarro and Quintana-Domeque (2010) who show that urban road pavement provision in Mexico improves the life of the nearby residents and reduce their commuting costs. See also Jalan and Ravallion (2002) who argue that road constructions can reduce poverty in developing countries.
} 
Define the elasticity of urban employment with respect to commuting costs as:

$$
\eta_{L \tau}=-\frac{\partial L^{C}}{\partial \tau} \frac{\tau}{L^{C}}
$$

We have: ${ }^{13}$

Proposition 1 Assume that the productivity difference between rural and urban areas is large enough. ${ }^{14}$ Assume further that $\eta_{L \tau}>1$. Then, a decrease in transportation costs $\tau$ leads to:

(i) an increase in job creation in the $\operatorname{city} \theta^{C *}$;

(ii) an ambiguous effect on $L^{C *}$ and on $L^{R *}$. However, if $\left|\frac{\partial \theta^{C *}}{\partial \tau}\right|$ is low enough, then $\frac{\partial L^{C *}}{\partial \tau}<$ 0 , and $\frac{\partial L^{R *}}{\partial \tau}>0$.

Result $(i)$ is quite intuitive. If urban employment is very sensitive to commuting costs $\left(\eta_{L \tau}>1\right)$, then reducing commuting costs increases job creation in cities. Indeed, when commuting costs decrease, it becomes cheaper to hire workers (remember that part of the bargained wage was to compensate workers for their commuting costs) and thus more firms enter the labor market. The effects of $\tau$ on urban and rural employment are ambiguous because there are two opposite effects: a direct positive one and an indirect negative one through $\theta^{C *}$. Formally, we have:

$$
\begin{aligned}
\frac{\partial L^{C}}{\partial \tau}= & \underbrace{-\frac{1}{(1-s) \tau^{2}}\left[y^{C}-\frac{\gamma}{(1-\beta)}\left[\frac{r+\delta+\beta a\left(\theta^{C}\right)}{q\left(\theta^{C}\right)}\right]\right]}_{\text {Direct positive effect }} \\
& \underbrace{-\frac{\gamma}{(1-s)(1-\beta)}\left[\frac{a^{\prime}\left(\theta^{C}\right) q\left(\theta^{C}\right)-\left[r+\delta+\beta a\left(\theta^{C}\right)\right] q^{\prime}\left(\theta^{C}\right)}{\left[q\left(\theta^{C}\right)\right]^{2}}\right] \gamma \frac{\partial \theta^{C *}}{\partial \tau}}_{\text {Indirect negative effect }}
\end{aligned}
$$

When $\tau$ decreases, there is a direct positive effect on urban employment since, as stated above, it becomes cheaper for firms to hire workers. However, because job creation increases, there is also an indirect negative effect on employment. Indeed, as $\theta^{C *}$ increases following

\footnotetext{
${ }^{13}$ The proofs of all propositions can be found in the Appendix.

${ }^{14}$ The exact condition is given in the Appendix. See (49).
} 
a decrease in $\tau$, wages rise (see (26)) and it becomes more difficult to fill a vacancy since $q^{\prime}\left(\theta^{C}\right) \leq 0$. The net effect is thus ambiguous but if $\left|\frac{\partial \theta^{C *}}{\partial \tau}\right|$ is low enough, then obviously the first effect dominates the second one and $\frac{\partial L^{C}}{\partial \tau}<0$. Furthermore, because of the steady-state flows equation (28), the effect of $\tau$ on $L^{R *}$ has the opposite sign in order for (28) to be satisfied.

What is crucial in a transportation policy is that it directly affects the housing and the labor market. Indeed, when $\tau$ is reduced, the price of land/housing decreases everywhere in the city (see (16)). This, in turn, affects wages since firms need to compensate less workers for their spatial costs and therefore wages decrease (see (26)). As a result, firms create more jobs and thus $\theta^{C *}$ increases. This has an indirect negative effect on wages. These both effects (lower land rents and higher chance of finding a job) induce rural workers to migrate to the city, which eventually reduce urban employment. This implies, in particular, that there are amplifying effects because of the interaction between the land and labor markets.

\subsection{Subsidizing firms' entry cost}

Another interesting policy to be considered is the one that reduces the entry cost $\gamma$ of firms in the city. For example, the government could encourage investment and job creation in cities by helping new firms to establish there. This has been a common policy in Europe and in the United States where governments (for example, Ireland with IBM) have attracted firms in certain areas by giving them a tax relief during a pre-defined period of time. Enterprise Zone (EZ) programs aiming at revitalizing depressed local areas also supply tax relief and other subsidies to targeted depressed areas (see, e.g. Boarnet and Bogart, 1996; Potter and Moore, 2000; Bondonio, D. and R.T. Greenbaum, 2007; Busso et al., 2010).

In our model, we have the following result.

Proposition 2 Assume that the productivity difference between rural and urban areas is large enough. ${ }^{15}$ Then, a decrease in the firms' entry cost $\gamma$ in the city leads to:

(i) an increase in job creation in the city $\theta^{C *}$;

(ii) an ambiguous effect on $L^{C *}$ and on $L^{R *}$. However, if $\left|\frac{\partial \theta^{C *}}{\partial \gamma}\right|$ is low enough, then $\frac{\partial L^{C *}}{\partial \gamma}<$ 0, and $\frac{\partial L^{R *}}{\partial \gamma}>0$.

\footnotetext{
${ }^{15}$ The exact condition is given in the Appendix. See (49).
} 
When the government reduces firms' entry cost in the city, more firms holding a vacant job enter the labor market and therefore more jobs are created ( $\theta^{C *}$ increases). The effect on urban employment is, however, ambiguous because of the indirect negative effect of $\theta^{C *}$. Indeed, we have:

$$
\begin{aligned}
\frac{\partial L^{C *}}{\partial \gamma}= & \underbrace{-\frac{\left[r+\delta+\beta a\left(\theta^{C}\right)\right]}{(1-s) \tau(1-\beta) q\left(\theta^{C}\right)}}_{\text {Direct positive effect }} \\
& \underbrace{-\frac{\gamma}{(1-s) \tau(1-\beta)}\left[\frac{a^{\prime}\left(\theta^{C}\right) q\left(\theta^{C}\right)-\left[r+\delta+\beta a\left(\theta^{C}\right)\right] q^{\prime}\left(\theta^{C}\right)}{\left[q\left(\theta^{C}\right)\right]^{2}}\right] \frac{\partial \theta^{C *}}{\partial \gamma}}_{\text {Indirect negative effect }}
\end{aligned}
$$

When $\gamma$ decreases, there is a direct positive effect on urban employment since more jobs are created and workers find jobs at a higher rate. There is, however, an indirect negative effect through $\theta^{C *}$ since, when job creation increases, wages also increase and it becomes more difficult to fill a vacancy since $q^{\prime}\left(\theta^{C}\right) \leq 0$. As a result, the net effect is ambiguous. If, however, $\left|\frac{\partial \theta^{C *}}{\partial \gamma}\right|$ is low enough, which means that the positive effect on job creation is not too strong, then a decrease in the entry cost increases urban employment and decreases rural employment. As with the transportation policy, $L^{C *}$ and $L^{R *}$ are negatively related through the steady-state flows equation (28), and thus we have the opposite sign for the effect of $\tau$ on $L^{R *}$.

Observe that the entry-cost policy operates very differently than the transportation policy. Indeed, the latter has a direct impact on the land market and thus affects rural-urban migration through the resulting increase in housing prices. The former has no direct impact on the housing market and affects migration through the increase in job creation. Furthermore, because the transportation policy has a direct impact on the land market, the effects of a reduction of $\tau$ on labor-market outcomes are amplified and are much stronger than in the entry-cost policy. We will investigate further these issues when we compare these two policies.

\subsection{Restricting rural-urban migration}

We would like now to consider another policy aiming at directly restricting the migration to the cities. For example, in China, internal migration is regulated through a hukou system. 
Instituted in 1958, the hukou requires every citizen seeking a change in residence to obtain a permission from the public security bureau. Hukou is effectively an internal passport system that makes the process of moving between or within provinces analogous to the process of moving between countries (Henderson, 2009; Zenou, 2010). In other words, the rural workers who migrate to a city without a hukou are considered as "illegal" migrants by the local authorities. The Chinese government has tried to reduce rural-urban migration by imposing some costs on these "illegal" migrants. In particular, the latter do not have access to social services and schools for their children. For example, one of the requirements for having access to social housing is that at least one member of the household living in a city must have a local permanent non-agricultural hukou registration for more than five years.

The United States has also tried to restrict migration, especially Mexican migrants (see, e.g. Durand et al., 1999). Even though this type of migration is between two different countries, the mechanism is relatively similar. In that case, there is a relatively small cost to be caught (mainly deportation) so the United States has put more resources in trying to catch and deport illegal migrants. The same applies to Europe, especially Spain and Italy with illegal migrants from Africa.

Denote by $0<\alpha<1$ the probability of catching a migrant and $C$ the cost for a migrant to be caught (the $\operatorname{cost} C$ is the utility loss of a migrant who has been caught). In that case, the expected utility of migrating is not anymore $I_{U}^{C}$ but

$$
\alpha\left[\int_{0}^{+\infty}\left(w_{L}^{R}-R_{A}\right) e^{-r t} d t-C\right]+(1-\alpha) I_{U}^{C}
$$

Indeed, when someone decides to migrate to the city, with probability $\alpha$, he/she will be caught, and, in that case, will be "deported" (i.e. sent back to the rural area) and will obtain a utility equals to that of living in rural areas minus the utility loss $C$. With probability $1-\alpha$, the migrant is not caught and will obtain the expected utility of residing in cities $I_{U}^{C}$. As a result, the rural-urban equilibrium condition can now be written as:

$$
\alpha\left[\int_{0}^{+\infty}\left(w_{L}^{R}-R_{A}\right) e^{-r t} d t-C\right]+(1-\alpha) I_{U}^{C}=\int_{0}^{+\infty}\left(w_{L}^{R}-R_{A}\right) e^{-r t} d t
$$

Rearranging these terms and by remembering that $R_{A}=0$, this equation is equivalent to:

$$
r I_{U}^{C}=w_{L}^{R}+\frac{\alpha}{(1-\alpha)} r C
$$


By using (6), (18), (19), (26), equation (33) is given by:

$$
\begin{aligned}
& {\left[F^{\prime R}\left(L^{R}\right)+\frac{\alpha}{(1-\alpha)} r C+s \tau\left(N-L^{R}\right)\right]\left[r+\delta+a\left(\theta^{C}\right)\right] } \\
= & a\left(\theta^{C}\right) \beta\left[y^{C}+\gamma s \theta^{C}-(1-s) \tau L^{C}\right]
\end{aligned}
$$

The two other equations that determine $L^{C}$ (job creation) and $L^{R}$ (flow equation) are not directly affected. As a result, the steady-state equilibrium is now defined by three unknowns $\theta^{C *}, L^{C *}$, and $L^{R *}$ and three equations (27), (28), and (34). We have the following result:

Proposition 3 Assume that the productivity difference between rural and urban areas is large enough. ${ }^{16}$ Then, an increase in $\alpha$, the probability to be caught and/or $C$, the cost of being caught for a migrant leads to:

(i) an increase in job creation in the city $\theta^{C *}$;

(ii) a decrease in urban employment $L^{C *}$.

(iii) an increase in rural employment $L^{R *}$.

The effect on job creation $\theta^{C *}$ is quite straightforward. Indeed, when $\alpha$ or $C$ increases, less people migrate to the city. There is less competition for jobs and thus it is easier for urban firms to fill their vacancies. As a result, more firms enter the urban labor market and job creation increases in the city. The effect on rural employment is also quite easy to understand. Even though more opportunities exist in the city (higher $\theta^{C *}$ ), the direct effect of deterring migration (through either an increase in $\alpha$ or $C$ ) is high enough to increase rural employment. Concerning the impact on $L^{C *}$, the effect is more subtle because an increase in $\alpha$ or $C$ affects $L^{C *}$ only indirectly through $\theta^{C *}$ and $L^{R *}$. There are two opposite forces. On the one hand, an increase in $\alpha$ or $C$ positively affects $\theta^{C *}$, which increases $L^{C *}$. On the other hand, an increase in $\alpha$ or $C$ positively affects $L^{R *}$, which decreases $L^{C *}$ (because, in steady-state, flows in and out employment have to be equal). The second effect turns out to be stronger and thus the net effect is negative.

\footnotetext{
${ }^{16}$ The exact condition is given in the Appendix. See (49).
} 


\section{Understanding the different policies}

Let us now compare the three policies: subsidizing transportation, subsidizing firms' entry cost and restricting migration. We assume that the government has a fixed amount of money $M$ that it wants to spend on a given policy. We will now add a government budget constraint, analyze each policy and compare them.

\subsection{Transportation policy}

The government gives a subsidy $\sigma^{C}$ for each commuter (employed or unemployed) so that the commuting cost of an employed worker is now $\left(1-\sigma^{C}\right) \tau$ and that of an unemployed worker is $\left(1-\sigma^{C}\right) s \tau$, where $0<\sigma^{C}<1$ is the subsidy. The government's budget constraint can be written as:

$$
M=\sigma^{C} \tau L^{C}+\sigma^{C} s \tau\left(N-L^{C}-L^{R}\right)
$$

which is equivalent to:

$$
\sigma^{C *}=\frac{M}{\tau\left[(1-s) L^{C *}+s\left(N-L^{R *}\right)\right]}
$$

Since $\sigma^{C}$ is between 0 and $1, M<\tau\left[(1-s) L^{C}+s\left(N-L^{R}\right)\right]$. Observe that, for a given $M, \sigma^{C *}$ is negatively affected by $L^{C *}$ and positively by $L^{R *}$. Indeed, when urban employment increases, more employed and less unemployed workers need to be subsidized but the former commute more than the latter. As a result, when $L^{C *}$ increases, $\sigma^{C *}$ has to decrease for $M$ to stay constant. The opposite occurs with $L^{R *}$ since it only affects urban unemployed workers $\left(U^{C *}=N-L^{C *}-L^{R *}\right)$.

In that case, the three equilibrium conditions that determine $\theta^{C *}, L^{C *}$ and $L^{R *}$ are now given by:

$$
\begin{gathered}
y^{C}=\frac{\gamma}{q\left(\theta^{C *}\right)}\left[\frac{r+\delta+\beta a\left(\theta^{C *}\right)}{1-\beta}\right]+(1-s) \tau\left(1-\sigma^{C *}\right) L^{C *} \\
L^{C *}=\frac{a\left(\theta^{C *}\right)}{\delta+a\left(\theta^{C *}\right)}\left(N-L^{R *}\right)
\end{gathered}
$$




$$
\begin{aligned}
& a\left(\theta^{C *}\right) \beta\left[y^{C}+\gamma s \theta^{C *}-(1-s)\left(1-\sigma^{C *}\right) \tau L^{C *}\right] \\
= & {\left[F^{\prime R}\left(L^{R}\right)+s \tau\left(1-\sigma^{C *}\right)\left(N-L^{R}\right)\right]\left[r+\delta+a\left(\theta^{C *}\right)\right] }
\end{aligned}
$$

where $\sigma^{C}$ is given by (35). The transportation policy directly affect job creation $\theta^{C *}$ (see (36)) since it becomes cheaper to hire workers (urban wages decrease because of lower spatial compensation) and rural-urban migration $L^{R *}$ (see (38)) since it is cheaper to live in cities (lower housing prices and commuting costs). Urban employment $L^{C *}$ is affected by this policy indirectly through $\theta^{C *}$ and $L^{R *}$. The new aspect here is that commuting costs are now also affected by $L^{C *}$ and $L^{R *}$ through the subsidy $\sigma^{C *}$.

\subsection{Subsidizing firms' entry cost}

Consider the second policy, which consists in subsidizing firms' entry cost in cities, i.e. reducing $\gamma$. In that case, firms with a vacancy now pay $\left(1-S^{C}\right) \gamma$ instead of $\gamma$ to enter the labor market, where $0<S^{C}<1$ is the subsidy. The government's budget constraint can be written as:

$$
M=S^{C} \gamma V^{C}
$$

Since $\theta^{C}=V^{C} / s U^{C}=V^{C} / s\left(N-L^{C}-L^{R}\right)$, we obtain:

$$
S^{C *}=\frac{M}{\gamma s \theta^{C *}\left(N-L^{C *}-L^{R *}\right)}
$$

Since $\sigma^{C}$ is between 0 and $1, M<\gamma s \theta^{C *}\left(N-L^{C *}-L^{R *}\right)$. Observe that, for a given $M$, $S^{C *}$ is positively affected by both $L^{C *}$ and $L^{R *}$. Indeed, when urban or rural employment increases, urban unemployment decreases, and thus the number of vacancies hold by firms is reduced. As a result, when $L^{C *}$ or $L^{R *}$ increases, $S^{C *}$ has to increase for $M$ to stay constant.

The three equilibrium conditions that determine $\theta^{C *}, L^{C *}$ and $L^{R *}$ are now given by:

$$
\begin{gathered}
y^{C}=\frac{\left(1-S^{C *}\right) \gamma}{q\left(\theta^{C *}\right)}\left[\frac{r+\delta+\beta a\left(\theta^{C *}\right)}{1-\beta}\right]+(1-s) \tau L^{C *} \\
L^{C *}=\frac{a\left(\theta^{C *}\right)}{\delta+a\left(\theta^{C *}\right)}\left(N-L^{R *}\right) \\
a\left(\theta^{C *}\right) \beta\left[y^{C}+\left(1-S^{C *}\right) \gamma s \theta^{C *}-(1-s) \tau L^{C *}\right]=\left[F^{\prime R}\left(L^{R}\right)+s \tau\left(N-L^{R}\right)\right]\left[r+\delta+a\left(\theta^{C *}\right)\right]
\end{gathered}
$$


where $S^{C *}$ is given by (39). The entry-cost policy directly affect job creation $\theta^{C *}$ (see (40)) since it becomes cheaper to enter the labor market and rural-urban migration $L^{R *}$ (see (42)) since the expected utility to live in cities increases because it is easier to find a job there. Urban employment $L^{C *}$ is only affected indirectly through $\theta^{C *}$ and $L^{R *}$. Again, the new aspect here is that firms' entry costs are also affected by $L^{C *}$ and $L^{R *}$ through the subsidy $S^{C *}$.

\subsection{Restricting migration}

Let us now consider the last policy where the government spends a fixed amount of money $\Lambda$ to catch rural migrants. This implies that now $\alpha=\alpha(\Lambda)$ with $\alpha^{\prime}(\Lambda)>0$. The local government's budget constraint can thus be written as:

$$
M=\Lambda
$$

The three equilibrium conditions that determine $\theta^{C *}, L^{C *}$ and $L^{R *}$ are now given by:

$$
\begin{gathered}
y^{C}=\frac{\gamma}{q\left(\theta^{C *}\right)}\left[\frac{r+\delta+\beta a\left(\theta^{C *}\right)}{1-\beta}\right]+(1-s) \tau L^{C *} \\
L^{C *}=\frac{a\left(\theta^{C *}\right)}{\delta+a\left(\theta^{C *}\right)}\left(N-L^{R *}\right) \\
{\left[F^{\prime R}\left(L^{R *}\right)+\frac{\alpha(M) r C}{1-\alpha(M)}+s \tau\left(N-L^{R *}\right)\right]\left[r+\delta+a\left(\theta^{C *}\right)\right]} \\
=a\left(\theta^{C *}\right) \beta\left[y^{C}+\gamma s \theta^{C *}-(1-s) \tau L^{C *}\right]
\end{gathered}
$$

The restricting-migration policy directly affects only rural-urban migration $L^{R *}$ (see (46)) since it becomes more costly for rural workers to migrate. Both job creation $\theta^{C *}$ (see (44)) and urban employment $L^{C *}$ (see (45)) are only indirectly affected by this policy through $L^{R *}$

\section{Comparing policies}

The transportation and entry-cost policies are relatively similar in the sense that they both directly affect job creation and migration. There is, however, an important difference between 
these two policies. The transportation policy directly affects the competition in the land market because it reduces transport costs for all workers while the entry-cost policy only indirectly affects the land market through job creation and migration. Finally, the restrictingmigration policy is quite different since it directly affects only rural-urban migration. For each policy, each steady-state equilibrium is determined by three equations so it is difficult to see, for a given $M$, which policy will increase most the welfare. We would like now to run some numerical simulations in order to give some intuitions of the mechanisms behind each policy.

As it is usual, we use the following Cobb-Douglas function for the matching function:

$$
\Omega\left(s U^{C}, V^{C}\right)=\left(s U^{C}\right)^{0.5}\left(V^{C}\right)^{0.5}
$$

This implies that $q\left(\theta^{C}\right)=\left(\theta^{C}\right)^{-0.5}, \theta^{C} q\left(\theta^{C}\right)=\left(\theta^{C}\right)^{0.5}$ and, the elasticity of the matching rate (defined as $\eta\left(\theta^{C}\right)=-q^{\prime}\left(\theta^{C}\right) \theta^{C} / q\left(\theta^{C}\right)$ ) is equal to 0.5 . The production function in the rural area is also a Cobb-Douglas function and it is defined as:

$$
F\left(L^{R}\right)=A\left(L^{R}\right)^{a}
$$

where $0<a<1$. The values of the parameters (in yearly terms) are the following. The total population $N$ is normalized to 100 . The relative bargaining power of workers is equal to $\eta\left(\theta^{C}\right)$, i.e. $\beta=\eta\left(\theta^{C}\right)=0.5$. The costs of maintaining a vacancy $\gamma$ are equal to 1 per unit of time while the urban productivity $y^{C}$ is 10 . Pecuniary commuting costs $\tau$ are equal to 0.1 whereas search effort $s$ is 0.5 (i.e. the unemployed workers make half as many CBD-trips as the employed workers). The discount rate is $r=0.01$, whereas the job-destruction rate rate is $\delta=0.15$, which means that, on average, there is a job is destroyed every six and half years.

Let us calculate the steady-state equilibrium. The numerical results of the steady-state equilibrium are displayed in Table 1.

\section{[Insert Table 1 here]}

If we take the economy as a whole, 67.04 percent of workers are employed in the city while 26.94 percent work in the rural area. The rest of the workers are unemployed. So the unemployment rate in the economy is 6.02 percent but the one in the urban area, as measured by the number of unemployed workers over the urban active population (and not 
the entire population), is 8.24 percent. There are roughly 34 percent of urban jobs that are vacant, and the number of vacant job per urban worker is 46 percent. There is an important productivity difference between the rural and the urban sectors, which results in stark wage differences (urban wages are nearly five times higher than rural wages). The housing costs in the city are quite high in the employment area but very low in the unemployment area, capturing the idea that new migrants live in relatively distressed areas (shanty towns). For example, when a rural worker migrates to the city, he/she lives in the unemployment area where the highest land price is at $x=L^{C}$, which is $R_{L}^{C *}\left(L^{C *}\right)=R_{U}^{C *}\left(L^{C *}\right)=0.301$. For an employed worker who lives in the more expensive location in the city, i.e. $x=0$, the housing price is 7 , which is roughly 23 times more expensive.

In Table 1, we also give different welfare values. First, the equilibrium total welfare in the city $T S^{C *}$ is given by (wages and land rents are just transfers): ${ }^{17}$

$$
T S^{C *}=\int_{0}^{+\infty} e^{-r t}\left\{\int_{0}^{L^{C^{*}}}\left(y^{C}-\tau x\right) d x+\int_{L^{C^{*}}}^{N-L^{R^{*}}}(-s \tau x) d x-\gamma \theta^{C^{*}} s u^{C^{*}}\right\} d t
$$

while the equilibrium total welfare in rural areas $T S^{R *}$ is the total production there since wages are just transfers:

$$
T S^{R *}=\int_{0}^{+\infty} e^{-r t} F\left(L^{R^{*}}\right) d t=\frac{F\left(L^{R^{*}}\right)}{r}
$$

Therefore, $T S_{\text {Total }}^{*}=T S^{C *}+T S^{R *}$ is the total welfare in the economy. We also give the total land rent in the city, which is

$T L R^{C *}=\frac{1}{r}\left[\int_{0}^{L^{C^{*}}}\left[\tau\left(L^{C^{*}}-x\right)+s \tau\left(N-L^{R *}-L^{C^{*}}\right)\right] d x+\int_{L^{C^{*}}}^{N-L^{R *}}\left[s \tau\left(N-L^{R^{*}}-x\right)\right] d x\right]$

We would like now to compare the different policies at a given cost $M$. Table 2a displays the results when the government has some finite budgetary resources equal to $M=4$. This table illustrates well the way each policy operates, as already highlighted in sections 4.1, 4.2, and 4.3. First, it can be seen that the transportation policy is the most efficient one since it increases the total welfare most (either measured by the total welfare in the city $T S C^{*}$ or in the economy $T S_{\text {Total }}^{*}$ ). It also increases urban employment (from 67.04 percent to 86.15 percent) and reduces urban unemployment (from 8.24 percent to 7.70 percent) most.

\footnotetext{
${ }^{17}$ It is assumed here that the welfare in the city is the sum of utilities of workers, firms and landlords, even if the latter do not live in the city (i.e. we have assumed absentee landlords).
} 
Quite naturally, when transportation is subsidized both rural employment and rural welfare $T S^{R^{*}}$ decrease. If we look at the two other policies, the effects on urban employment and unemployment are either small (entry-cost policy) or even negative (restricting-migration policy). These results show that the transportation policy can have a very big impact on labor outcomes in cities and therefore on welfare because it acts simultaneously on the land and labor markets, creating amplifying effects. Indeed, when $\tau$ is reduced, the housing price (land market) decreases everywhere in the city and the urban wage (labor market) also decrease. These are direct effects. On the contrary, when firms' entry costs are reduced, only job creation (labor market) is directly affected. Finally, when migration is restricted, none of the markets is directly affected, only migration is. This can explain why this last policy has relatively small effects on labor-market outcomes in cities and large effects on outcomes in rural-areas.

Second, for the same budget $M=4$, the government needs to subsidize 45 percent of commuting costs for all workers $\left(\sigma^{C^{*}}=0.45\right)$ but only 11 percent of firms' entry costs $\left(S^{C^{*}}=0.11\right)$. This shows that for the transportation policy to be efficient, very important improvements in public transport systems should be realized.

\section{[Insert Table $2 a$ here]}

To check the robustness of our results, we have performed the same exercise for a higher budget, $M=8$, i.e. twice as much. The qualitative results remain unchanged with the transportation policy being still the most efficient. The effects are, of course, much more drastic with an important reduction in urban unemployment and in total land rent and a huge increase in welfare for both urban residents and the economy as a whole. With the transportation policy, few people end up living in rural areas because it becomes very attractive to live in the city. In that case, the government need to subsidy up to 85 percent of the commuting costs of all workers in the city.

\section{[Insert Table $2 b$ here]}

We would like to conduct further robustness checks to see if indeed the transportation policy is the most efficient policy. We would like first to vary the government budget from $M=0$ to 10 (roughly, from 0 to $1 \%$ of potential GDP). Figures $2 \mathrm{a}, 2 \mathrm{~b}$, and $2 \mathrm{c}$ present the simulation results with respectively the unemployment rate, the total land rent value in the 
city and the total welfare in the economy on the vertical axis and $M$ on the horizontal axis. In all these figures, the horizontal line (that does not vary with $M$ ) is the market solution (i.e. when $M=0$ ). The thin solid curve describes the transportation policy while the thick one corresponds to the restricting-migration policy. Finally, the dash curve represents the entry-cost policy.

\section{[Insert Figures $2 a, 2 b, 2 c$ here]}

The results we find are in accordance with the previous ones (described in tables 2a and $2 \mathrm{~b})$. In all dimensions, the transportation policy is the most efficient one whatever the level of expenses of the government and, in fact, the higher the level of expenses $M$, the larger is the gap between the different policies. Indeed, if we look at the unemployment rate (Figure 2a), its value is relatively close to that of the entry-cost policy but after $M=3$, the gap widens in favor of the transportation policy. As for the restricting-migration policy, its effect on unemployment is pretty small, just slightly below that of the market solution $(8.24 \%)$. When $M$ is equal to 10 , the unemployment rate $u^{C^{*}}$ is $6.65 \%$ when the transportation policy is implemented while it is $7.18 \%$ and $8.15 \%$ for the entry-cost and the restricting-migration policy, respectively. Concerning the total land rent in the city $T L R^{C^{*}}$ (Figure $2 \mathrm{~b}$ ), it is interesting to notice that it is always above the market solution when the entry-cost policy is implemented while it is always below for the restricting-migration policy. As for the transportation policy, it sharply increases for low value of $M$ and then decreases to reach very low values as soon as $M$ is above 3 . Finally, the total welfare in the economy $T S_{\text {Total }}^{*}$ (Figure 2c) when the transportation policy is considered is always above that of the other policies and the gap sharply widens when $M$ increases. It can be seen that, as compared to the market solution, there is very little gain in terms of $T S_{\text {Total }}^{*}$ when either the entrycost or the restricting-migration policy is implemented. All these results indicate that the transportation policy is the most efficient policy and, as stated above, it is due to the fact that it impacts directly on the land and the labor market, creating amplifying effects.

We would like to explore other parts of parameter space to see if our results are robust. In our simulations, we assumed that the entry cost $\gamma$ is 1 (10\% of a worker's annual output). This is relatively small and this could explain why subsidizing it would have little impact on welfare. In Figure 3, we report the simulation results when $\gamma$ varies between nearly zero and 10. We fix the government budget to $M=4 .{ }^{18}$ It can be seen that, again, there is a

\footnotetext{
${ }^{18}$ We have performed the same numerical simulations for different values of $M$ and the results are roughly
} 
large gap in terms of total welfare between the transportation policy and the other ones, even though, not surprisingly, for all of them, welfare decreases with firms' entry costs.

\section{[Insert Figure 3 here]}

Another potentially important parameter is the Nash bargaining parameter $\beta$, that we have fixed to 0.5 , as it is usually the case in numerical simulations of search models. For example, Besley and Burgess (2004) have shown that it has an important impact on Indian labor rights. We vary $\beta$ between values close to zero and close to 1 and analyze its impact on total welfare. Figure 4 reports the results. We find the same type of results indicating that the transportation policy is still the most efficient one.

\section{[Insert Figure 4 here]}

Even though these are just numerical simulations, we believe that they give some intuition of the mechanisms behind each policy. We think that the transportation policy is the most efficient one because it acts directly on both the land and labor market. These results also illustrate the fact that migration is not a bad thing per se, especially if it is accompanied by policies that improve the quality of life in cities. As we have seen in the different simulations, the restricting-migration policy increases the number of people living in rural areas but has a small impact on urban employment and unemployment and may even educe the total welfare in the economy. Thus, improving the transport infrastructure in cities can have important positive effects on urban employment despite the induced migration from rural areas.

\section{Concluding remarks}

In this paper, we develop a rural-urban migration model where the city is characterized by both a search-matching labor market and a land/housing market. We determine the steady-state equilibrium and study its properties. We then consider three different policies: a transport policy that improves the public transport system, an entry-cost policy that encourages investment in cities and a restricting-migration policy that imposes some costs on migrants. We find that these policies can have important positive effects on urban employment and job creation while reducing rural employment. Because we explicitly model both 
the land and labor markets in the city, the mechanisms through which these positive effects operate are complex since there are amplifying effects due to the interaction between these two markets. We believe, however, that the transportation policy is the most efficient one. Indeed, when the local government increases the commuting cost subsidy, the land price decreases everywhere in the city since the accessibility to the job center is less costly. As a result, the cost of residing in the city is lower for new migrants so that the flow of migrants sharply increases. However, because commuting costs are lower, firms need to compensate less workers for their spatial costs and thus the decrease in wages lead to more job creation. The former effect being much potent than the latter, the final effect of subsidizing commuting costs is to increase urban employment and decrease rural employment. Our main message here is that (local) governments should take into account the interaction between the two markets when implementing a policy because of the resulting amplifying effects. In particular, improving the transport infrastructure in cities can have important positive effects on urban employment in developing countries despite the induced migration from rural areas.

\section{References}

[1] Acharya, R. (2000), "Indian railways: where the commuter is king," Japan Railways and Transport Review 25, 34-45.

[2] Albrecht, J., Navarro, L. and S. Vroman (2009), "The effects of labour market policies in an economy with an informal Sector," Economic Journal 119, 1105-1129.

[3] Banerjee, B. (1984), "Information flow, expectations and job search : Rural-to-urban migration process in India," Journal of Development Economics 15, 239-257.

[4] Basu, K. (1997), Analytical Development Economics. The Less Developed Economy Revisited, Cambridge, MA: MIT Press.

[5] Besley, T. and R. Burgess (2004), "Can labor regulation hinder economic performance? Evidence from India," Quarterly Journal of Economics 119, 91-134.

[6] Boarnet, M.G. and W.T. Bogart (1996), "Enterprise zones and employment: Evidence from New Jersey," Journal of Urban Economics 40, 198-215. 
[7] Bondonio, D. and R.T. Greenbaum (2007), "Do local tax incentives affect economic growth? What mean impact miss in the analysis of enterprise zone policies" Regional Science and Urban Economics 37, 121-136.

[8] Borck, R. and M. Wrede (2005), "Political economy of commuting costs," Journal of Urban Economics 57, 478-499.

[9] Borck, R. and M. Wrede (2009), "Subsidies for intracity and intercity commuting," Journal of Urban Economics 66, 25-32.

[10] Bosch, M., Goni E., and W. F. Maloney (2007), "The determinants of rising informality in Brazil: Evidence from gross worker flows," World Bank Discussion Paper 4375.

[11] Bosch, M. and W.F. Maloney (2008), "Cyclical movements in unemployment and informality in developing countries," Unpublished paper, World Bank.

[12] Brueckner, J.K. (2005), "Transport subsidies, system choice, amd urban sprawl," Regional Science and Urban Economics 35, 715-733.

[13] Brueckner, J.K. and H. Selod (2006), "The political economy of urban transport-system choice," Journal of Public Economics 90, 983-1005.

[14] Busso, M., Gregory, J. and P. Kline (2010), "Assessing the incidence and efficiency of a prominent place based policy," Unpublished manuscript, University of California, Berkeley.

[15] Carruthers, R., Dick, M. and A. Saurkar (2005), "Affordability of public transport in developing countries," Transport Papers Series No. TP-3, World Bank.

[16] Coulson, E., Laing, D. and P. Wang (2001), "Spatial mismatch in search equilibrium," Journal of Labor Economics 19, 949-972.

[17] De Borger, B. (2009), "Commuting, congestion tolls and the structure of the labour market: Optimal congestion pricing in a wage bargaining model," Regional Science and Urban Economics 39, 434-448.

[18] Durand, J., Massey, D.S. and E.A. Parrado (1999), "The new era of Mexican migration to the United States," Journal of American History 86, 518-536. 
[19] Fields, G.S. (1975), "Rural-urban migration, urban unemployment and underemployment, and job-search activity in LDCs," Journal of Development Economics 2, 165-187.

[20] Fields, G.S. (1989), "On-the-job search in a labor market model. Ex ante Choices and ex post outcomes," Journal of Development Economics 30, 159-178.

[21] Fujita, M. (1989), Urban Economic Theory, Cambridge: Cambridge University Press.

[22] Gonzalez-Navarro, M. and C. Quintana-Domeque (2010), "Roads to development: Experimental evidence from urban road pavement," Unpublished manuscript, University of California, Berkeley.

[23] Harris, J.R. and M.P. Todaro (1970), "Migration, unemployment and development: A two-sector analysis," American Economic Review 60, 126-142.

[24] Henderson, J.V. (2009), "Urbanization in China: Policy issues and options," Unpublished manuscript, Brown University.

[25] Jalan, J. and M. Ravallion (2002), "Geography poverty traps? A micro model of consumption growth in rural China," Journal of Applied Econometrics 17, 329-346.

[26] Laing, D., Park, C. and P. Wang (2005), "A modified Harris-Todaro model of ruralurban migration for China," In: F. Kwan and E. Yu (Eds.), Critical Issues in China's Growth and Development, London: Ashgate, pp. 245-264.

[27] Maloney, W. (2004), "Informality revisited," World Development 32, 1159-78.

[28] Mohtadi, H. (1989), "Migration and job search in a dualistic economy. A Todaro-Stigler synthesis," Economics Letters 29, 373-378.

[29] Mortensen, D.T. and C.A. Pissarides (1999), "New developments in models of search in the labor market," In: D. Card and O. Ashenfelter (Eds.), Handbook of Labor Economics, Amsterdam: Elsevier Science, pp. 2567-2627.

[30] Office of the Registrar General of India (2001), "Urban agglomerations. Cities having population of more han one million in 2001 in the Census of India 2001," New Delhi, India. Available at: http://www.censusindia.net/results. 
[31] Ortega J. (2000), "Pareto-improving immigration in an economy with equilibrium unemployment," Economic Journal 110, 92-112.

[32] Pissarides, C.A. (2000), Equilibrium Unemployment Theory, Second edition, M.I.T. Press, Cambridge.

[33] Potter, J. and B. Moore (2000), "UK enterprise zones and the attraction of inward investment," Urban Studies 37, 1279-312.

[34] Pucher, J., Korattyswaropam, N., Mittal, N. and N. Ittyerah (2005), "Urban transport crisis in India," Transport Policy 12, 185-198.

[35] Rama, M. (1998), "How bad is unemployment in Tunisia? Assessing labor market efficiency in a developing country," World Bank Research Observer 13, 59-77.

[36] Ray, D. (1998), Development Economics, Princeton: Princeton University Press.

[37] Satchi, M. and J. Temple (2009), "Labor markets and productivity in developing countries," Review of Economic Dynamics 12, 183-204.

[38] Sato, Y. (2004), "Migration, frictional unemployment, and welfare-improving labor policies," Journal of Regional Science 44, 773-793.

[39] Todaro, M.P. (1969), "A model of labor migration and urban unemployment in less developed countries," American Economic Review 59, 138-148.

[40] Van Ommeren, J. and P. Rietveld (2005), "The commuting time paradox," Journal of Urban Economics 58, 437-454.

[41] Van Ommeren, J., Rietveld, P. and P. Nijkamp (1999), "Job moving, residential moving, and commuting: A search perspective," Journal of Urban Economics 46, 230-253.

[42] Wahba, J. and Y. Zenou (2005), "Density, social networks and job search methods: Theory and applications to Egypt," Journal of Development Economics 78, 443-473.

[43] Wasmer, E. and Y. Zenou (2002), "Does city structure affect job search and welfare?" Journal of Urban Economics 51, 515-541. 
[44] Wasmer, E. and Y. Zenou (2006), "Equilibrium search unemployment with explicit spatial frictions," Labour Economics 13, 143-165.

[45] Wrede, M. (2001), "Should commuting expenses be tax deductible? A welfare analysis" Journal of Urban Economics 49, 80-99.

[46] Zenou, Y. (2000), "Urban unemployment, agglomeration and transportation policies," Journal of Public Economics 77, 97-133.

[47] Zenou, Y. (2008), "Job search and mobility in developing countries: Theory and policy implications," Journal of Development Economics 86, 336-355.

[48] Zenou, Y. (2009), Urban Labor Economics, Cambridge: Cambridge University Press.

[49] Zenou, Y. (2010), "Housing policies in China: Issues and options," Unpublished manuscript, Stockholm University. 


\section{APPENDIX}

\section{Proofs of Propositions 1, 2 and 3}

Before proving these propositions, let us first analyze the steady-state equilibrium. The steady-state equilibrium can be characterized by only one condition, (30), which can be written as:

$$
\begin{gathered}
\Phi\left(\theta^{C}, \tau, \gamma\right) \\
\equiv \quad\left\{F^{\prime R}\left(L^{R}\left(\theta^{C}, \tau, \gamma\right)\right)+s \tau\left[N-\left(L^{R}\left(\theta^{C}, \tau, \gamma\right)\right)\right]\right\}\left[r+\delta+a\left(\theta^{C}\right)\right] \\
\quad-a\left(\theta^{C}\right) \beta\left[\left(y^{C}+\gamma s \theta^{C}\right)-(1-s) \tau L^{C}\left(\theta^{C}, \tau, \gamma\right)\right] \\
=0
\end{gathered}
$$

where from the job-creation condition (27), we can define:

$$
L^{C}\left(\theta^{C}, \tau, \gamma\right)=\frac{y^{C}}{(1-s) \tau}-\frac{\gamma}{(1-s) \tau(1-\beta)}\left[\frac{r+\delta+\beta a\left(\theta^{C}\right)}{q\left(\theta^{C}\right)}\right]
$$

with

$$
\frac{\partial L^{C}}{\partial \theta^{C}}<0 \quad, \quad \frac{\partial L^{C}}{\partial \tau}<0 \quad, \quad \frac{\partial L^{C}}{\partial \gamma}<0
$$

and from the steady-state condition on flows (28), we have

$$
L^{R}\left(\theta^{C}, \tau, \gamma\right)=N-\left[\frac{\delta+a\left(\theta^{C}\right)}{a\left(\theta^{C}\right)}\right] L^{C}\left(\theta^{C}, \tau, \gamma\right)
$$

with

$$
\begin{gathered}
\frac{\partial L^{R}}{\partial \theta^{C}}=\left[\frac{\delta a^{\prime}\left(\theta^{C}\right)}{a\left(\theta^{C}\right)}\right] L^{C}-\left[\frac{\delta+a\left(\theta^{C}\right)}{a\left(\theta^{C}\right)}\right] \frac{\partial L^{C}}{\partial \theta^{C}}>0 \\
\frac{\partial L^{R}}{\partial \tau}=-\left[\frac{\delta+a\left(\theta^{C}\right)}{a\left(\theta^{C}\right)}\right] \frac{\partial L^{C}}{\partial \tau}>0 \\
\frac{\partial L^{R}}{\partial \gamma}=-\left[\frac{\delta+a\left(\theta^{C}\right)}{a\left(\theta^{C}\right)}\right] \frac{\partial L^{C}}{\partial \gamma}>0
\end{gathered}
$$

By differentiating (47), we have:

$$
\frac{\partial \Phi\left(\theta^{C}, \tau, \gamma\right)}{\partial \theta^{C}} \equiv \Phi_{\theta}
$$


with

$$
\begin{aligned}
\Phi_{\theta}= & {\left[F^{\prime \prime R}(.)-s \tau\right] \frac{\partial L^{R}}{\partial \theta^{C}}\left[r+\delta+a\left(\theta^{C}\right)\right]+a^{\prime}\left(\theta^{C}\right)\left[F^{\prime R}\left(L^{R}\right)+s \tau\left(N-L^{R}\right)\right] } \\
& -a^{\prime}\left(\theta^{C}\right) \beta\left[\left(y^{C}+\gamma s \theta^{C}\right)-(1-s) \tau L^{C}\right] \\
& -a\left(\theta^{C}\right) \beta \gamma s+a\left(\theta^{C}\right) \beta(1-s) \tau \frac{\partial L^{C}}{\partial \theta^{C}}
\end{aligned}
$$

This is equivalent to:

$$
\begin{aligned}
\Phi_{\theta}= & {\left[F^{\prime \prime R}(.)-s \tau\right] \frac{\partial L^{R}}{\partial \theta^{C}}\left[r+\delta+a\left(\theta^{C}\right)\right]+\beta a\left(\theta^{C}\right)(1-s) \tau \frac{\partial L^{C}}{\partial \theta^{C}}-a\left(\theta^{C}\right) \beta \gamma s } \\
& -a^{\prime}\left(\theta^{C}\right)\left[\beta\left(y^{C}+\gamma s \theta^{C}\right)-\beta(1-s) \tau L^{C}-F^{\prime R}\left(L^{R}\right)-s \tau\left(N-L^{R}\right)\right]
\end{aligned}
$$

A sufficient condition for $\Phi_{\theta}<0$ is:

$$
\beta\left(y^{C}+\gamma s \theta^{C}\right)-\beta(1-s) \tau L^{C}-F^{\prime R}\left(L^{R}\right)-s \tau\left(N-L^{R}\right)>0
$$

Observe that, from the urban wage (26), we have

$$
w_{L}^{C}=\beta\left(y^{C}+\gamma s \theta^{C}\right)+(1-\beta)(1-s) \tau L^{C}
$$

which is equivalent to:

$$
\beta\left(y^{C}+\gamma s \theta^{C}\right)=w_{L}^{C}-(1-\beta)(1-s) \tau L^{C}
$$

Plugging this value in (48) and observing that $w_{L}^{R}=F^{\prime R}\left(L^{R}\right)$, we obtain:

$$
w_{L}^{C}-w_{L}^{R}-s \tau\left(N-L^{R}\right)-(1-s) \tau L^{C}>0
$$

which is equivalent to:

$$
w_{L}^{C}-w_{L}^{R}>\tau\left(L^{C}+s U^{C}\right)
$$

As a result, a sufficient condition for $\Phi_{\theta}<0$ is $w_{L}^{C}-w_{L}^{R}>\tau\left(L^{C}+s U^{C}\right)$, i.e. the urban-rural productivity difference is large enough.

- Let us now prove Proposition 1.

We have:

$$
\frac{\partial \theta^{C}}{\partial \tau}=-\frac{\Phi_{\tau}}{\Phi_{\theta}}
$$


where

$$
\Phi_{\tau} \equiv \frac{\partial \Phi\left(\theta^{C}, \tau, \gamma\right)}{\partial \tau}
$$

Since $\Phi_{\theta}<0$, the sign of $\frac{\partial \theta^{C}}{\partial \tau}$ is the same as the sign of $\Phi_{\tau}$. We have:

$$
\Phi_{\tau}=\frac{\partial L^{R}}{\partial \tau}\left[F^{\prime \prime R}(.)-s \tau\right]\left[r+\delta+a\left(\theta^{C}\right)\right]+a\left(\theta^{C}\right) \beta(1-s)\left(L^{C}+\tau \frac{\partial L^{C}}{\partial \tau}\right)
$$

Define

$$
\eta_{L \tau}=-\frac{\partial L^{C}}{\partial \tau} \frac{\tau}{L^{C}}
$$

the elasticity of urban employment with respect to commuting costs, then a sufficient condition for

$$
\frac{\partial \theta^{C *}}{\partial \tau}<0
$$

is $\eta_{L \tau}>1$.

By differentiating (27), we obtain:

$$
\begin{aligned}
\frac{\partial L^{C}}{\partial \tau}= & -\frac{1}{(1-s) \tau^{2}}\left[y^{C}-\frac{\gamma}{(1-\beta)}\left[\frac{r+\delta+\beta a\left(\theta^{C}\right)}{q\left(\theta^{C}\right)}\right]\right] \\
& -\frac{\gamma}{(1-s)(1-\beta)}\left[\frac{a^{\prime}\left(\theta^{C}\right) q\left(\theta^{C}\right)-\left[r+\delta+\beta a\left(\theta^{C}\right)\right] q^{\prime}\left(\theta^{C}\right)}{\left[q\left(\theta^{C}\right)\right]^{2}}\right] \gamma \frac{\partial \theta^{C *}}{\partial \tau}
\end{aligned}
$$

which is clearly ambiguous.

Finally, by differentiating (28), we get:

$$
\frac{\partial L^{R *}}{\partial \tau}=\frac{\delta a^{\prime}\left(\theta^{C}\right)}{\left[a\left(\theta^{C}\right)\right]^{2}} \frac{\partial \theta^{C *}}{\partial \tau} L^{C *}-\left[\frac{\delta+a\left(\theta^{C}\right)}{a\left(\theta^{C}\right)}\right] \frac{\partial L^{C *}}{\partial \tau}
$$

If $\left|\frac{\partial \theta^{C *}}{\partial \tau}\right|$ is high enough, then $\frac{\partial L^{C *}}{\partial \tau}>0$ and thus $\frac{\partial L^{R *}}{\partial \tau}<0$.

- Let us prove Proposition 2.

We have:

$$
\frac{\partial \theta^{C}}{\partial \gamma}=-\frac{\Phi_{\gamma}}{\Phi_{\theta}}
$$

where

$$
\Phi_{\gamma} \equiv \frac{\partial \Phi\left(\theta^{C}, \tau, \gamma\right)}{\partial \gamma}
$$

Since $\Phi_{\theta}<0$, the sign of $\frac{\partial \theta^{C}}{\partial \gamma}$ is the same as the sign of $\Phi_{\gamma}$. We have:

$$
\begin{aligned}
\Phi_{\gamma} & =\frac{\partial L^{R}}{\partial \gamma}\left[F^{\prime \prime R}(.)-s \tau\right]\left[r+\delta+a\left(\theta^{C}\right)\right]-a\left(\theta^{C}\right)\left[\beta s \theta^{C}-\beta(1-s) \tau \frac{\partial L^{C}}{\partial \gamma}\right] \\
& <0
\end{aligned}
$$


As a result,

$$
\frac{\partial \theta^{C *}}{\partial \gamma}<0
$$

Differentiating (27), we get:

$$
\begin{gathered}
L^{C}=\frac{y^{C}}{(1-s) \tau}-\frac{\gamma}{(1-s) \tau q\left(\theta^{C}\right)}\left[\frac{r+\delta+\beta a\left(\theta^{C}\right)}{1-\beta}\right] \\
\frac{\partial L^{C}}{\partial \gamma}=-\frac{\left[r+\delta+\beta a\left(\theta^{C}\right)\right]}{(1-s) \tau(1-\beta) q\left(\theta^{C}\right)} \\
-\frac{\gamma}{(1-s) \tau(1-\beta)} \frac{\partial \theta^{C *}}{\partial \gamma}\left[\frac{a^{\prime}\left(\theta^{C}\right) q\left(\theta^{C}\right)-\left[r+\delta+\beta a\left(\theta^{C}\right)\right] q^{\prime}\left(\theta^{C}\right)}{\left[q\left(\theta^{C}\right)\right]^{2}}\right]
\end{gathered}
$$

This is again ambiguous. If $\left|\frac{\partial \theta^{C *}}{\partial \gamma}\right|$ is low enough, then $\frac{\partial L^{C *}}{\partial \gamma}<0$. result due to direct and indirect effects.

Finally, by differentiating (28), we get:

$$
\frac{\partial L^{R *}}{\partial \tau}=\frac{\delta a^{\prime}\left(\theta^{C}\right)}{\left[a\left(\theta^{C}\right)\right]^{2}} \frac{\partial \theta^{C *}}{\partial \gamma} L^{C *}-\left[\frac{\delta+a\left(\theta^{C}\right)}{a\left(\theta^{C}\right)}\right] \frac{\partial L^{C *}}{\partial \gamma}
$$

If $\left|\frac{\partial \theta^{C *}}{\partial \gamma}\right|$ is high enough, then $\frac{\partial L^{C *}}{\partial \gamma}>0$, and thus $\frac{\partial L^{R *}}{\partial \tau}<0$.

- Let us finally prove Proposition 3.

Observe that (47) is now defined as:

$$
\begin{gathered}
\Phi\left(\theta^{C}, \tau, \gamma, C, \alpha\right) \equiv-a\left(\theta^{C}\right) \beta\left[y^{C}+\gamma s \theta^{C}-(1-s) \tau L^{C}\left(\theta^{C}, \tau, \gamma\right)\right] \\
+\left\{F^{\prime R}\left(L^{R}\left(\theta^{C}, \tau, \gamma\right)\right)+\frac{\alpha}{(1-\alpha)} r C+s \tau\left[N-L^{R}\left(\theta^{C}, \tau, \gamma\right)\right]\right\}\left[r+\delta+a\left(\theta^{C}\right)\right]=0
\end{gathered}
$$

It is easily verified that, as before, a sufficient condition for $\Phi_{\theta}<0$ if (49). Furthermore, by differentiating (50), we obtain:

$$
\Phi_{C}=\frac{\alpha}{(1-\alpha)} r\left[r+\delta+a\left(\theta^{C}\right)\right]>0 \text { and } \Phi_{\alpha}=\frac{r C}{(1-\alpha)^{2}}\left[r+\delta+a\left(\theta^{C}\right)\right]>0
$$

Observe that both $L^{C}$ and $L^{R}$ are not directly affected by either $\alpha$ or $C$. We thus have:

$$
\frac{\partial \theta^{C}}{\partial C}=-\frac{\Phi_{C}}{\Phi_{\theta}}>0
$$


and

$$
\frac{\partial \theta^{C}}{\partial \alpha}=-\frac{\Phi_{\alpha}}{\Phi_{\theta}}>0
$$

Moreover, by differentiating (27), we obtain:

$$
\frac{\partial L^{C}}{\partial C}=-\gamma \frac{\partial \theta^{C}}{\partial C}\left[\frac{\beta a^{\prime}\left(\theta^{C}\right) q\left(\theta^{C}\right)-\left[r+\delta+\beta a\left(\theta^{C}\right)\right] q^{\prime}\left(\theta^{C}\right)}{(1-s)(1-\beta) \tau\left[q\left(\theta^{C}\right)\right]^{2}}\right]<0
$$

and

$$
\frac{\partial L^{C}}{\partial \alpha}=-\gamma \frac{\partial \theta^{C}}{\partial \alpha}\left[\frac{\beta a^{\prime}\left(\theta^{C}\right) q\left(\theta^{C}\right)-\left[r+\delta+\beta a\left(\theta^{C}\right)\right] q^{\prime}\left(\theta^{C}\right)}{(1-s)(1-\beta) \tau\left[q\left(\theta^{C}\right)\right]^{2}}\right]<0
$$

By differentiating (28), we obtain:

$$
\begin{aligned}
& \frac{\partial L^{R}}{\partial C}=\frac{\delta a^{\prime}\left(\theta^{C}\right)}{\left[a\left(\theta^{C}\right)\right]^{2}} \frac{\partial \theta^{C}}{\partial C} L^{C}-\left[\frac{\delta+a\left(\theta^{C}\right)}{a\left(\theta^{C}\right)}\right] \frac{\partial L^{C}}{\partial C}>0 \\
& \frac{\partial L^{R}}{\partial \alpha}=\frac{\delta a^{\prime}\left(\theta^{C}\right)}{\left[a\left(\theta^{C}\right)\right]^{2}} \frac{\partial \theta^{C}}{\partial \alpha} L^{C}-\left[\frac{\delta+a\left(\theta^{C}\right)}{a\left(\theta^{C}\right)}\right] \frac{\partial L^{C}}{\partial \alpha}>0
\end{aligned}
$$


Table 1. Steady-state equilibrium

\begin{tabular}{||c||c||}
\hline \hline$L^{C *}$ & 67.04 \\
\hline$L^{R *}$ & 26.94 \\
\hline$\theta^{C *}$ & 11.16 \\
\hline$U^{C *}$ & 6.02 \\
\hline$u^{C *}$ & 8.24 \\
\hline$V^{C *}$ & 33.59 \\
\hline$v^{C *}$ & 45.98 \\
\hline$w_{L}^{R *}$ & 1.93 \\
\hline$y^{R *}$ & 3.85 \\
\hline$w_{L}^{C *}$ & 9.47 \\
\hline$I_{L}^{C *}$ & 196.00 \\
\hline$I_{U}^{C *}$ & 192.65 \\
\hline \hline$T L R^{C}$ & 24,577 \\
\hline \hline$T S^{C *}$ & 42,425 \\
\hline \hline$T S^{R *}$ & 10,381 \\
\hline \hline$T S_{T o t a l}^{*}$ & 52,806 \\
\hline \hline
\end{tabular}


Table 2a. Comparing policy measures at given cost $M=4\left(\sigma^{C *}=45 \%, S^{C *}=11 \%, \Lambda=4\right)$

\begin{tabular}{|c|c|c|c|c|c|c|c|c|c|c|}
\hline & $L^{C *}$ & $L^{R *}$ & $\theta^{*}$ & $u^{C *}$ & $v^{C *}$ & $T L R^{C *}$ & $T S^{C *}$ & $T S^{R *}$ & $T S_{\text {Total }}^{*}$ & $\begin{array}{c}\text { Policy } \\
\text { Ranking }\end{array}$ \\
\hline $\begin{array}{c}\text { Market } \\
\text { solution }\end{array}$ & 67.04 & 26.94 & 11.16 & 8.24 & 45.98 & 24,577 & 42,425 & 10,381 & 52,806 & \\
\hline $\begin{array}{c}\text { Transportation } \\
\text { policy }\end{array}$ & 86.15 & 6.66 & 12.92 & 7.70 & 49.77 & 22,358 & 63,746 & 5,162 & 68,908 & First \\
\hline $\begin{array}{c}\text { Entry-cost } \\
\text { policy }\end{array}$ & 67.66 & 26.63 & 12.61 & 7.79 & 49.12 & 24,904 & 42,723 & 10,320 & 53,043 & Second \\
\hline $\begin{array}{c}\text { Restricting } \\
\text { migration }\end{array}$ & 65.89 & 28.22 & 11.26 & 8.21 & 46.21 & 23,735 & 42,122 & 10,624 & 52,746 & Third \\
\hline
\end{tabular}

Base case: $y^{C}=10, \delta=0.15, A=20, a=0.5, N=100, \gamma=1$,

$$
r=0.01, \beta=0.5, s=0.5, \tau=0.5, \alpha=\frac{M}{1+M}, C=4 .
$$


Table 2b. Comparing policy measures at given cost $M=8\left(\sigma^{C *}=85 \%, S^{C *}=21 \%, \Lambda=8\right)$

\begin{tabular}{|c|c|c|c|c|c|c|c|c|c|c|}
\hline & $L^{C *}$ & $L^{R *}$ & $\theta^{*}$ & $u^{C *}$ & $v^{C *}$ & $T L R^{C *}$ & $T S^{C *}$ & $T S^{R *}$ & $T S_{\text {Total }}^{*}$ & \begin{tabular}{c} 
Policy \\
Ranking \\
\hline $\begin{array}{c}\text { Market } \\
\text { solution }\end{array}$
\end{tabular} \\
67.04 & 26.94 & 11.16 & 8.24 & 45.98 & 24,577 & 42,425 & 10,381 & 52,806 & \\
\hline $\begin{array}{c}\text { Transportation } \\
\text { policy }\end{array}$ & 91.26 & 1.90 & 16.02 & 6.97 & 55.86 & 6,957 & 84,246 & 2,758 & 87,004 & First \\
\hline $\begin{array}{c}\text { Entry-cost } \\
\text { policy }\end{array}$ & 68.24 & 26.33 & 14.21 & 7.37 & 52.38 & 25,207 & 42,998 & 10,263 & 53,261 & Second \\
\hline $\begin{array}{c}\text { Restricting } \\
\text { migration }\end{array}$ & 64.72 & 29.52 & 11.37 & 8.17 & 46.45 & 22,893 & 41,799 & 10,866 & 52,665 & Third \\
\hline
\end{tabular}

Base case: $y^{C}=10, \delta=0.15, A=20, a=0.5, N=100, \gamma=1$,

$$
r=0.01, \beta=0.5, s=0.5, \tau=0.5, \alpha=\frac{M}{1+M}, C=4 .
$$


Figure 1: The equilibrium land rent in the city and in the rural area

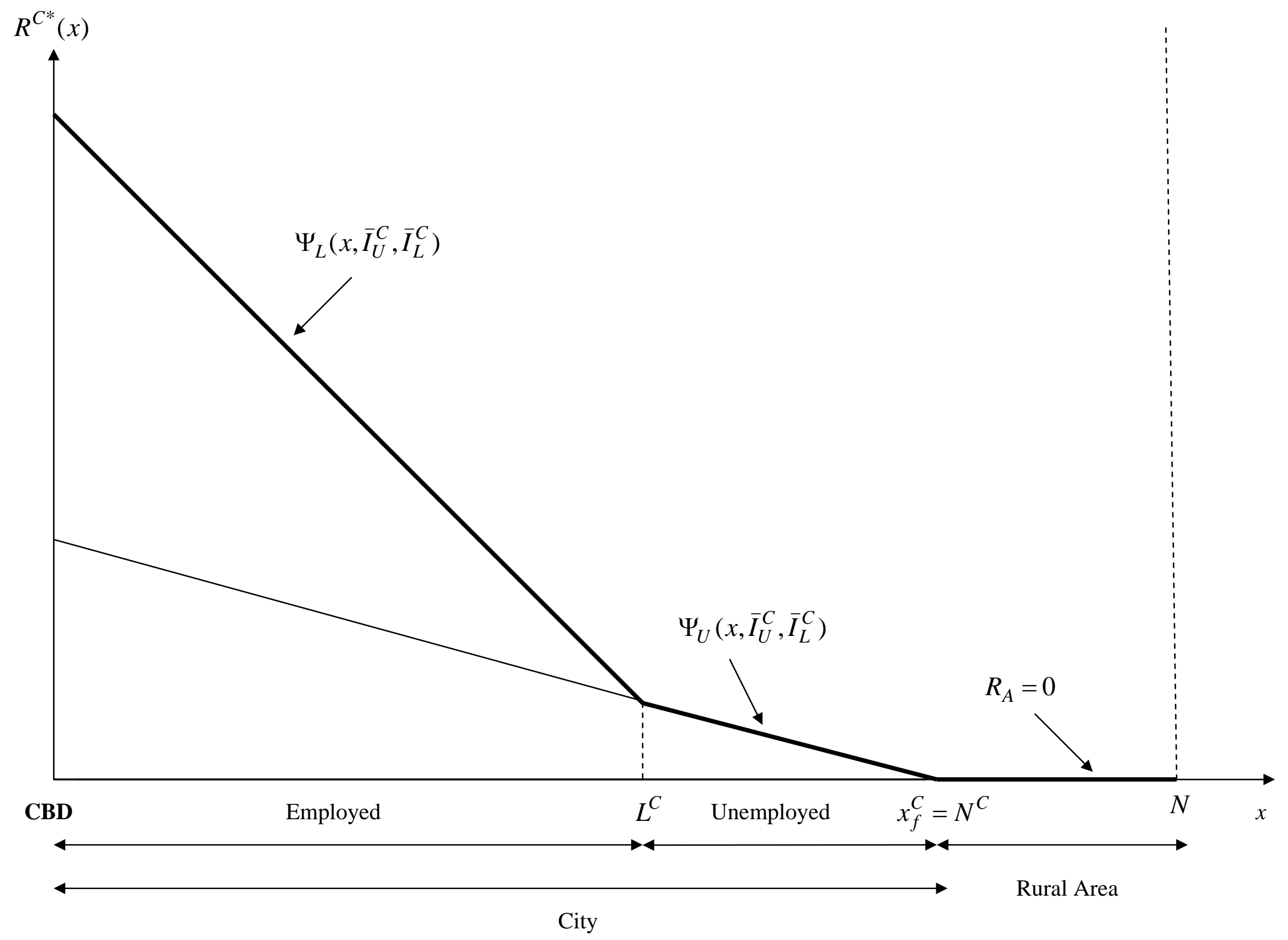


Figure 2a: Unemployment rate and government's spending under different policies

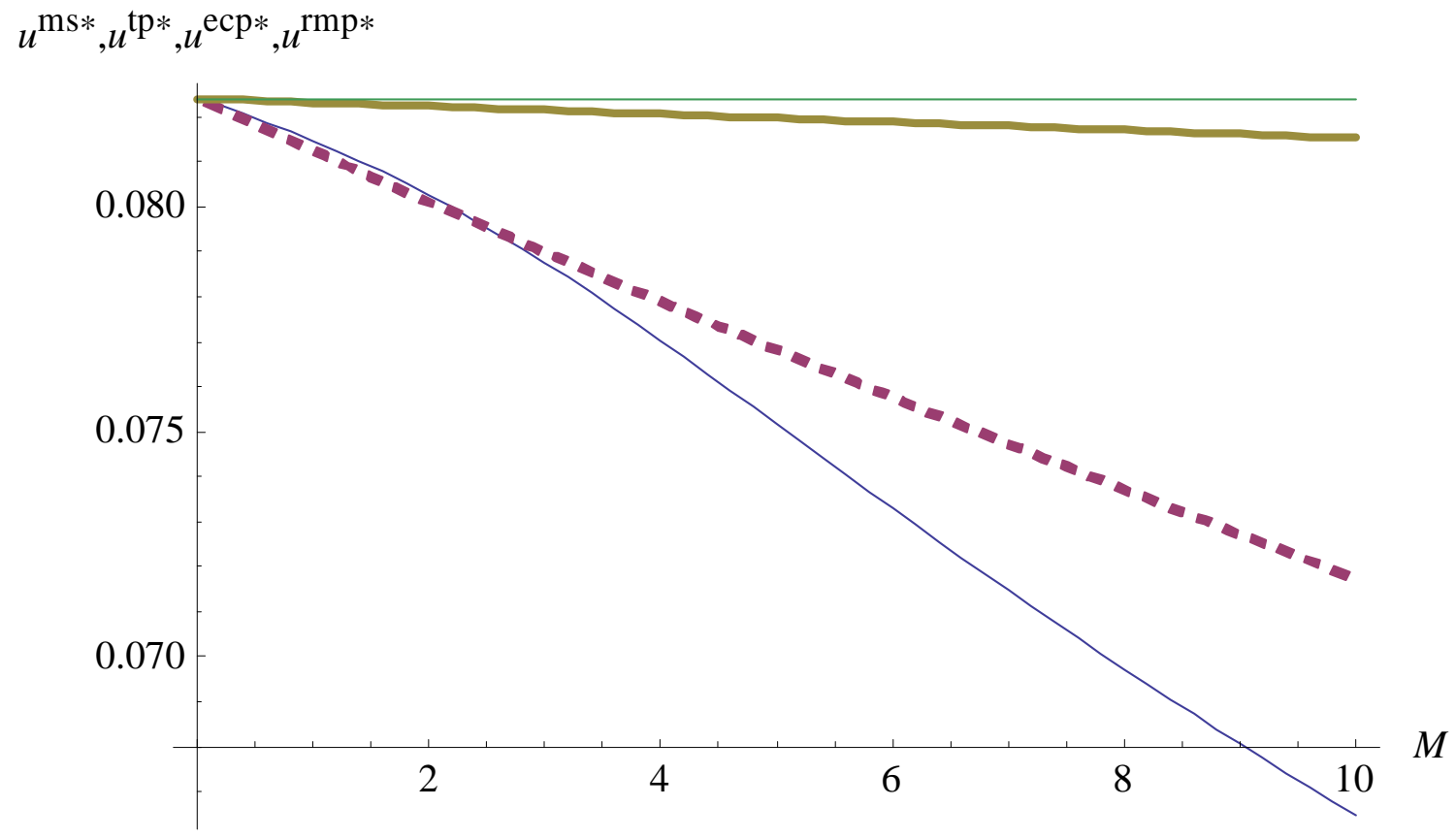

Figure 2b: Total land rent and government's spending under different policies

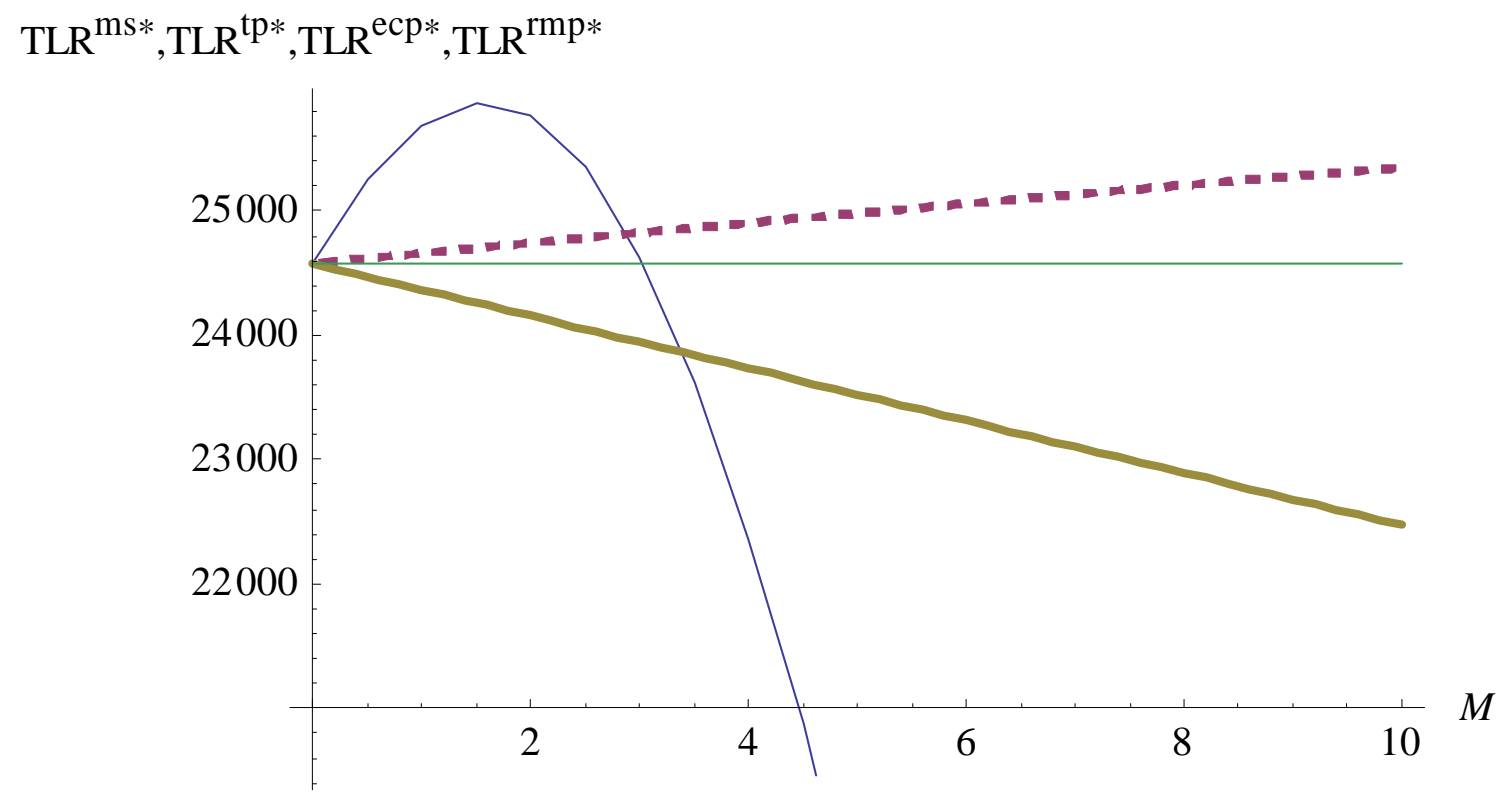


Figure 2c: Total welfare and government's spending under different policies

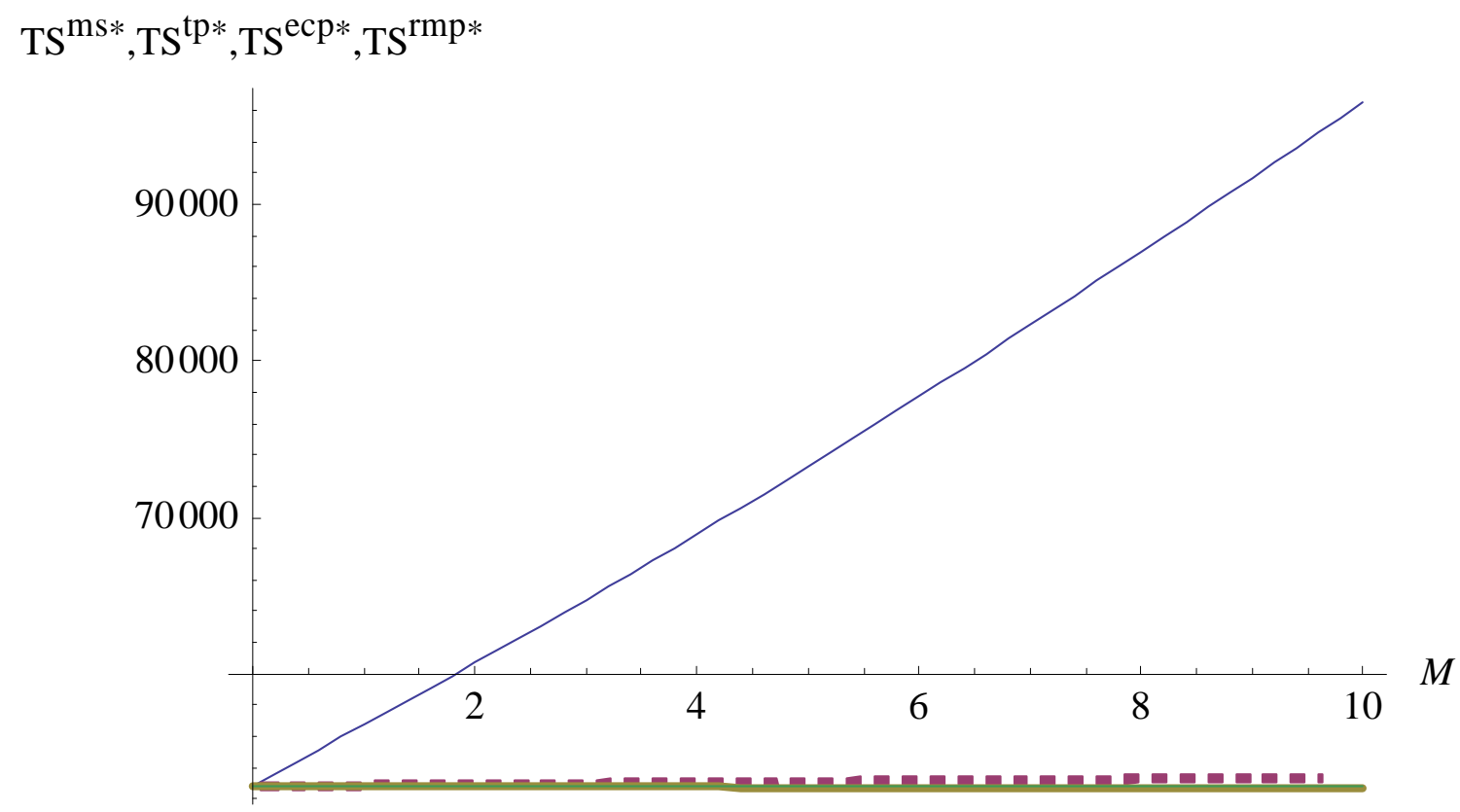


Figure 3: Total welfare and firms' entry costs under different policies $(M=4)$

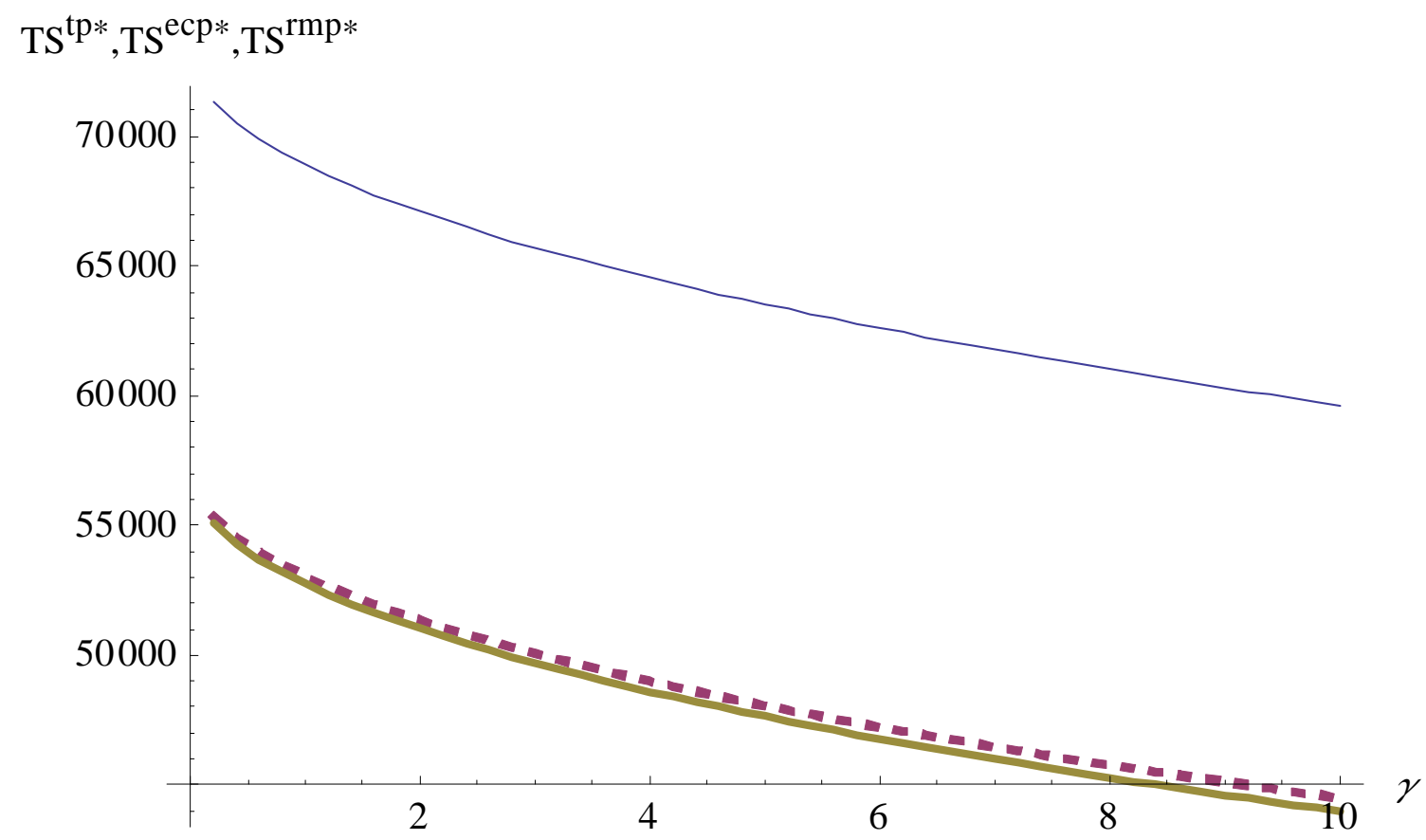

Figure 4: Total welfare and bargaining power under different policies $(M=4)$

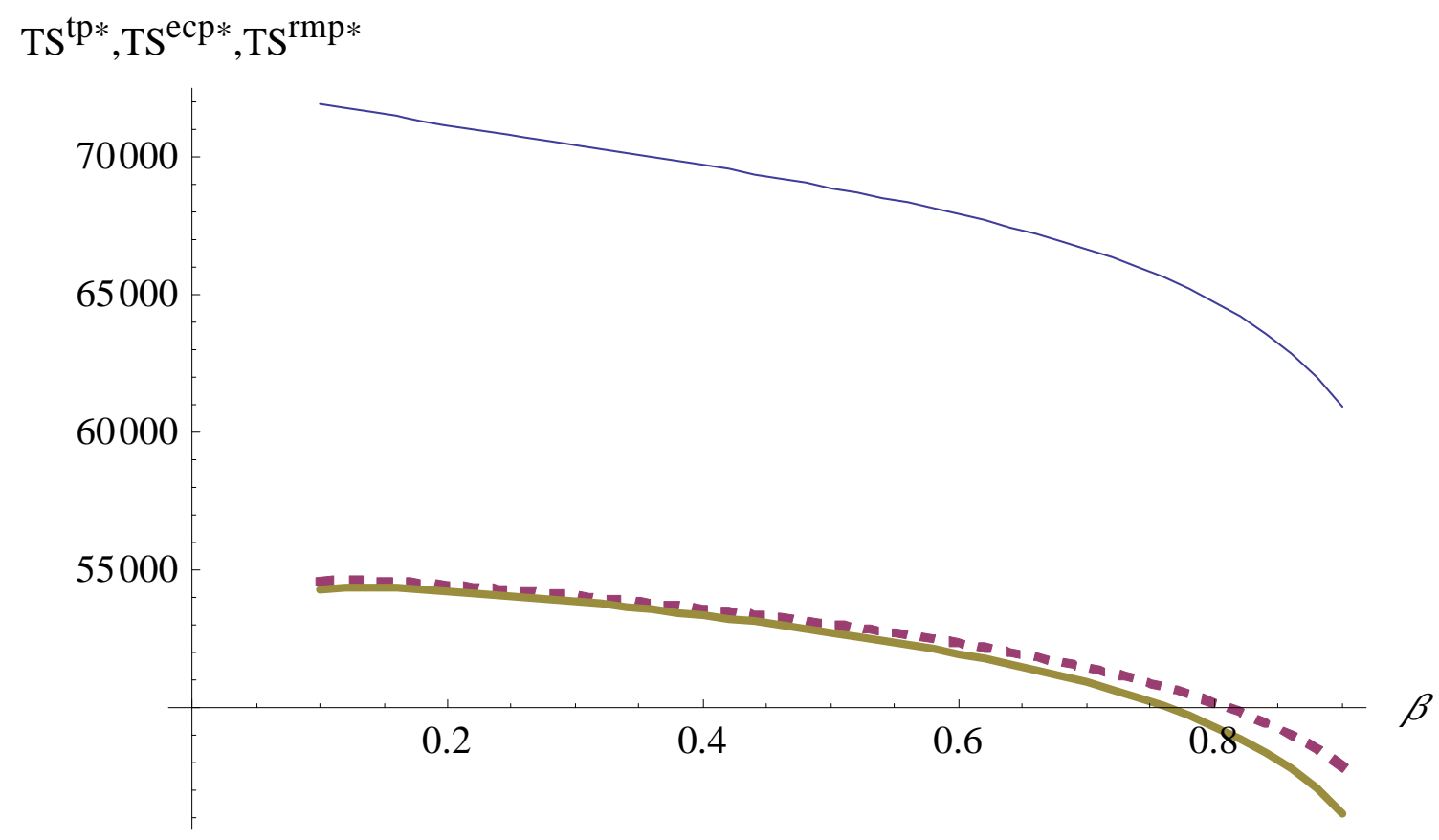

